Research article

\title{
Silencing of ascorbate oxidase results in reduced growth, altered ascorbic acid levels and ripening pattern in melon fruit
}

\author{
Fani Chatzopoulou ${ }^{\text {a,h, }}$, Maite Sanmartin ${ }^{\text {a,i, **,1 }}$, Ifigeneia Mellidou ${ }^{\mathrm{b}}$, Irini Pateraki ${ }^{\mathrm{a}, \mathrm{j}}$, \\ Athanasios Koukounaras $^{c}$, Georgia Tanou ${ }^{\mathrm{d}}$, Mary S. Kalamaki ${ }^{\mathrm{a}, \mathrm{k}}$, Sonja Veljović-Jovanović ${ }^{\mathrm{e}}$, \\ Tijana Cvetić Antić ${ }^{f}$, Stefanos Kostas ${ }^{c}$, Pavlos Tsouvaltzis ${ }^{c}$, Rebecca Grumet ${ }^{g}$, \\ Angelos K. Kanellis ${ }^{\text {a, }}$

\footnotetext{
${ }^{a}$ Group of Biotechnology of Pharmaceutical Plants, Laboratory of Pharmacognosy, Department of Pharmaceutical Sciences, Aristotle University of Thessaloniki, 541 24, Thessaloniki, Greece

${ }^{\mathrm{b}}$ Institute of Plant Breeding and Genetic Resources, HAO ELGO-DEMETER. Thermi, Thessaloniki, 57 001, Greece

${ }^{c}$ School of Agriculture, Aristotle University of Thessaloniki, 541 24, Thessaloniki, Greece

${ }^{\mathrm{d}}$ Institute of Soil and Water Resources, HAO ELGO-DEMETER. Thermi, Thessaloniki, 57 001, Greece

${ }^{\mathrm{e}}$ University of Belgrade -Department of Life Sciences, Institute for Multidisciplinary Research, 11000, Belgrade, Serbia

${ }^{\mathrm{f}}$ University of Belgrade - Faculty of Biology, Studenski Trg 16, 11000, Belgrade, Serbia

${ }^{\mathrm{g}}$ Department of Horticulture, Plant and Soil Sciences Building, Michigan State University, East Lansing, MI, 48824, USA

${ }^{\mathrm{h}}$ Laboratory of Microbiology, School of Medicine, Aristotle University of Thessaloniki, 541 24, Thessaloniki, Greece

${ }^{\mathrm{i}}$ Instituto de Biología Molecular y Celular de Plantas (IBMCP), Universidad Politécnica de Valencia (UPV)-Consejo Superior de Investigaciones Científicas (CSIC), Ciudad Politécnica de la Innovación, Ed. 8E, Ingeniero Fausto Elio $s / n$, Valencia, Spain

${ }^{\mathrm{j}}$ Department of Plant and Environmental Sciences, Faculty of Science, University of Copenhagen, Thorvaldsensvej 40, 1871, Copenhagen, Denmark

${ }^{\mathrm{k}}$ Division of Science \& Technology, American College of Thessaloniki, 17 Sevenidi Street, 55510, Thessaloniki, Greece
}

\section{A R T I C L E I N F O}

\section{Keywords:}

Cucumis melo

Ascorbate oxidase

Ascorbic acid

Ripening

Ethylene

\begin{abstract}
A B S T R A C T
Ascorbate oxidase (AO, EC 1.10.3.3) is a copper-containing enzyme localized at the apoplast, where it catalyzes the oxidation of ascorbic acid (AA) to dehydroascorbic acid (DHA) via monodehydroascorbic acid (MDHA) intermediate. Despite it has been extensively studied, no biological roles have been definitively ascribed. To understand the role of $\mathrm{AO}$ in plant metabolism, fruit growth and physiology, we suppressed $A O$ expression in melon (Cucumis melo L.) fruit. Reduction of AO activity increased AA content in melon fruit, which is the result of repression of AA oxidation and simultaneous induction of certain biosynthetic and recycling genes. As a consequence, ascorbate redox state was altered in the apoplast. Interestingly, transgenic melon fruit displayed increased ethylene production rate coincided with elevated levels of 1-aminocyclopropane-1-carboxylic acid (ACC) oxidase (ACO, EC 1.14.17.4) activity and gene expression, which might contribute to earlier ripening. Moreover, $A O$ suppressed transgenic melon fruit exhibited a dramatic arrest in fruit growth, due to a simultaneous decrease in fruit cell size and in plasmalemma (PM) ATPase activity. All the above, support for the first time, the in vivo AO participation in the rapid fruit growth of Cucurbitaceae and further suggest an alternative route for AA increase in ripening fruit.
\end{abstract}

Abbreviations: AAT, alcohol acyl-transferase; ACC, 1-aminocyclopropane-1-carboxylic acid; ACO, ACC oxidase; APX, ascorbate peroxidase; ATP, adenosine

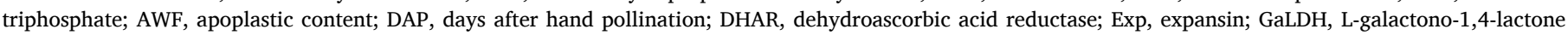

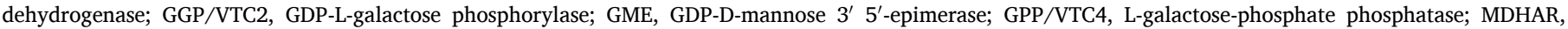
monodehydroascorbic acid reductase; MPG1, polygalacturonase; NPT, neomycin phosphotransferase; PM, plasmalemma; WT, wild-type.

* Corresponding author.

** Corresponding author. Instituto de Biología Molecular y Celular de Plantas (IBMCP), CSIC-Universidad Politécnica de Valencia, 46022, Valencia, Spain.

E-mail addresses: maisanar@upvnet.upv.es (M. Sanmartin), kanellis@pharm.auth.gr (A.K. Kanellis).

1 Equally contributed. 


\section{Introduction}

Ascorbic acid (AA), vitamin C, is a chemical compound required for human diet (Fenech et al., 2018; Mellidou et al., 2017, Mellidou et al., 2019; Smirnoff, 2018). AA is found in all cell compartments where acts as an antioxidant and scavenger against the so-called reactive oxygen species (ROS), which are natural by-products of aerobic cell metabolism and photosynthesis (Mellidou and Kanellis, 2017; Venkatesh and Park, 2014). Apoplastic AA that accounts for $10 \%$ of total AA content, acts as a first defense line against hostile environments. Apoplastic AA levels represent a sensitive mechanism by which abiotic and biotic stresses can be monitored and consequently activate plant defense-responses (Bellini and De Tullio, 2019; Foyer and Noctor, 2005). Changes in the levels and redox status of apoplastic AA in response to environmental stresses have been reported (Sanmartin et al., 2003). Moreover, several AA-deficient mutants and transgenic plants of Arabidopsis thaliana and Nicotiana tabacum showed increased sensitivity to ozone and to other oxidative stresses (Conklin et al., 1996; Fotopoulos et al., 2006; Sanmartin et al., 2003; Veljovic-Jovanovic et al., 2001) demonstrating the role of AA in plant defense (Macknight et al., 2017). Nonetheless, in the case of Arabidopsis vtc mutants, the different sensitivity to ozone cannot be solely justified by differences in AA levels, indicating the complexity of AA physiology and metabolism in plants (Conklin et al., 2000). In addition, as a unique enzyme cofactor, AA plays a crucial role in essential plant biosynthetic pathways such as the xanthophyll cycle, the ethylene biosynthesis and the synthesis of cell wall hydroxyproline rich proteins (HRGP) (Bulley and Laing, 2016; Smirnoff and Wheeler, 2000), pointing to AA involvement in plant development as well (Mellidou et al., 2017; Plumb et al., 2018). Indeed, Arabidopsis vtc mutants showed reduced cell growth as well as abnormalities in cell shape (Fenech et al., 2018; Mellidou and Kanellis, 2017).

There is also evidence supporting AA participation in cell division and/or cell expansion (Smirnoff, 2000, 2018). AA accumulates in actively growing meristems and in young tissues (De Gara and Tommasi, 1999), whereas root quiescent centers and dormant buds have little or no AA (Arrigoni et al., 1992; Kerk and Feldman, 1995). Early reports showed that cells normally competent to divide are held in the G1 phase of the cell cycle if AA content is lowered (Liso et al., 1984). Conversely, AA supplement to root cells resulted in a faster cell proliferation (Arrigoni et al., 1997; Kerk and Feldman, 1995) indicating a close correlation between AA levels and root meristem mitotic activity. The low AA levels in root quiescent centers and dormant buds were attributed to the presence of ascorbate oxidase (AO), an enzyme extensively studied with yet no ascribed biological roles. Regulation of $A O$ gene expression by growth promoters and suppressors (Pignocchi et al., 2003a; Sanmartin et al., 2007) pointed to a possible AO role in controlling cell expansion (Kato and Esaka, 1999, 2000; Smirnoff, 1996). Although the mechanism is not completely understood, oxidation of apoplastic AA by AO produces monodehydroascorbate (MDHA), and regeneration of MDHA back to AA could result in hyperpolarization of the plasma membrane and acidification of the apoplast, with the subsequent activation of the ion transport that leads to vacuole and cell enlargement (Gonzalez-Reyes et al., 1994).

Ascorbate oxidase is a unique plant enzyme found in high amounts in cucurbits (De Tullio et al., 2013). It was first described in cabbage (Svent-Györgi, 1931) and, since then numerous reports have dealt with its purification and characterization (Diallinas et al., 1997; Esaka et al., 1992; Lin and Varner, 1991; Moser and Kanellis, 1994). Fast growing plant tissues showed the highest AO activity independently of the organ nature, fruit or leaf. Melon AO activity and expression reach high levels during fruit development, just before the climacteric rise (Diallinas et al., 1997; Sanmartin et al., 2007), while cucumber AO mRNA, protein, and activity are mainly found in fruit epidermis (Yoshida et al., 1994). In this context, AO might play a significant role in controlling cell wall metabolism during fruit ripening and participate in the fast softening process observed in melon fruit, by the loss of hypodermal mesocarp membrane integrity (Lester and Stein, 1993).

Although the main biosynthetic pathway of AA in plants has been elucidated (Bulley and Laing, 2016; Mellidou et al., 2017; Smirnoff, 2018; Wheeler et al., 1998), regulation of AA biosynthesis or pool size in plants is poorly understood. Increasing the AA pool by exogenous AA application strongly inhibits its endogenous synthesis in embryonic axes of germinating pea seedlings (Pallanca and Smirnoff, 2000). Therefore, it seems that plants might control AA biosynthesis according to its endogenous pool size through a feedback mechanism (Bulley and Laing, 2016; Fenech et al., 2018; Pallanca and Smirnoff, 2000; Smirnoff, 2018). Due to its nutritional importance, a better understanding of AA biosynthesis and its metabolism will help in improving AA content of dietary plants. Engineering plants with increased AA level will not only improve the nutritional value but it will also favor plants' tolerance to abiotic and biotic stresses. Since the AA content in a cell is a result not only of its biosynthesis, but also of its catabolism and turnover, work is also needed to establish the role of the latter enzymes in controlling AA levels and redox state. To define this, we transformed melon plants with sense and antisense Cucumis melo AO4 (CmAO4) gene constructs to study the effects of altered AO levels in melon fruit. Our results indicate that $\mathrm{AO}$ contributes to the rapid growth of the curcubits by indirectly acting on $\mathrm{PM} \mathrm{H} \mathrm{H}^{+}$-ATPase activity through the hyperpolarization of plasmalemma and points out to an alternative route for controlling AA content during fruit development and ripening.

\section{Materials and methods}

\subsection{Plant material and cloning procedures}

Melon cv. Hale's Best Jumbo (Hollar Seed, Colorado, USA) and cv. Vedrantais Tezier (kindly provided by Prof. JC Pech, ENSAT Toulouse, France) seeds were used. Putative transgenic plants were transferred to sterile soil mix as soon as roots were well-developed and acclimated to greenhouse conditions. Flowers were hand-pollinated and tagged for date of fruit set and ripening state. For developmental and ripening studies, melon plants were grown in a greenhouse at $25^{\circ} \mathrm{C}$ day/night at the premises of the School of Agricultural Sciences, Aristotle University of Thessaloniki. Fruit were picked at various developmental stages [25-, 30-, 32-, 34-, 36-, 38-, and 40-days after hand pollination (DAP)], and the inner and outer areas of fruit mesocarp were separated using a scalpel blade, prior to snap-freezing in liquid nitrogen and stored at -80 ${ }^{\circ} \mathrm{C}$.

CmAO4 full-length cDNA (Sanmartin et al., 2007) in the sense orientation was transferred into the pGA643 plant transformation vector (An et al., 1988) as an XbaI fragment, and in the antisense orientation at the HindIII-HpaI sites, downstream of the constitutive CaMV $35 S$ promoter. Constructs were sequenced and introduced into two Agrobacterium tumefaciens strains, EHA105 and C58, by the freeze-thaw method (Holsters et al., 1978).

\subsection{Plant transformation}

Melon transformation was performed following previously described protocol (Fang and Grumet, 1990) with minor modifications. Seeds were decoated, sterilized in $15 \%(\mathrm{v} / \mathrm{v})$ commercial bleach $(5.25 \%$ sodium hypochlorite) with a drop of Tween-20 for $10 \mathrm{~min}$ and then rinsed three times with sterile distilled water. Seeds were placed on hormone free Murashige and Skoog (MS) medium (Murashige and Skoog, 1962) with $0.8 \%$ agar and allowed to germinate. The culture growth room conditions were $25{ }^{\circ} \mathrm{C}$ with a $16 \mathrm{~h}$-light/ $8 \mathrm{~h}$-dark photoperiod provided by cool white fluorescent lamps (ca. 2500 lux). Four-day old cotyledons were cut in 4-6 pieces and incubated for $10 \mathrm{~min}$ in a diluted overnight Agrobacterium culture (1:10 in LB). Explants were blotted on filter paper, transferred abaxially to regeneration media [MR, MS supplemented with $0.88 \mathrm{mg} / \mathrm{L}$ indole acetic acid (IAA), $1.22 \mathrm{mg} / \mathrm{L}$ benzylaminopurine (BAP) and $0.26 \mathrm{mg} / \mathrm{L}$ abscisic acid and $3 \%$ sucrose] without 
antibiotics and kept in co-culture for 3 days. Explants were washed three times with $\mathrm{dH}_{2} \mathrm{O}$, blotted dry and transferred onto MR with 175 or 200 $\mathrm{mg} / \mathrm{L}$ kanamycin and $400 \mathrm{mg} / \mathrm{L}$ timentin. Regenerated green shoots were separated and placed on filter paper on a layer of liquid elongation media (MS supplemented with $0.1 \mathrm{mg} / \mathrm{L}$ BAP, $3 \%$ sucrose) with antibiotics and kept for 2-3 weeks. Elongated green shoots were transferred to rooting media (hormone-free MS with $3 \%$ sucrose, $400 \mathrm{mg} / \mathrm{L}$ timentin). As roots started developing, leaf samples (20-30 mg) were evaluated for the presence of neomycin phosphotransferase (NPT II) protein by ELISA assay (5 Prime-3 Prime, Inc, Boulder, CO) performed according to manufacturer's instructions. Regenerated T0 plants were transferred to sterile soil mix and sealed in a plastic bag to acclimate to greenhouse conditions. To provide sufficient T0 transgenic fruit for evaluation, plants were vegetatively propagated using a commercial rooting powder [0.06\% (w/w) indole-3-butyric acid] and hand-pollinated to produce T1 progeny. For further characterization, $\mathrm{CoAO} 4$ transgenic plants were used.

\subsection{Genomic DNA isolation and PCR screening}

Genomic DNA was isolated from 1 to $2 \mathrm{~g}$ leaf tissue using the protocol described previously (Diallinas et al., 1997). For PCR screening, the presence of the sense insert was verified using $35 \mathrm{~S}$ primer $\left(5^{\prime}\right.$ ATCCTTCGCAAGACCCTTCC $\left.3^{\prime}\right)$ and PAOII primer $\left(5^{\prime}\right.$ GCAAATGGGGTTCAATATGGC $3^{\prime}$ ). For transgenic plants harboring the antisense construct, genomic DNA was amplified using the $35 \mathrm{~S}$ and the AO4-UTR primers (5' TCTAGACATCTTCCACACAAACTTCCCA 3'). PCR products were analyzed by Southern blot analysis as described earlier (Sambrook et al., 1989) to confirm that the amplified fragments corresponded to the expected transgene using as probe the ClaI-SphI fragment of $\mathrm{CmAO} 4 \mathrm{cDNA}$.

\subsection{Southern and RNA blot analysis}

Southern blot analysis of genomic DNA was performed to determine the T-DNA copy number. Genomic DNA $(10 \mu \mathrm{g})$ was digested with HindIII, a restriction enzyme that cut only once in the T-DNA but not in the transgene. Digested genomic DNA was fractionated in a $0.8 \%$ agarose TAE gel run overnight at $50 \mathrm{~V}$. The gel was transferred to a nylon membrane (Nytran ${ }^{\circledR} 0.45$ Schleicher \& Schuell) and hybridized at $65^{\circ} \mathrm{C}$ with a NPTII specific probe.

Total RNA was extracted from melon stems and fruit as described before (Diallinas et al., 1997; Sanmartin et al., 2003). Total RNA (15 $\mu \mathrm{g})$ was used on denaturing agarose/formaldehyde gels, transferred onto nylon membranes (Nytran ${ }^{\circledR}$ 0.45) and hybridized with specific radiolabeled probes (Supplementary Table 1) as applied previously (Sanmartin et al., 2003).

\subsection{Protein extraction and enzyme activity assay}

For total protein extraction, melon tissues $(1 \mathrm{~g})$ were ground in liquid nitrogen and extracted with 2 vol of extraction buffer containing $50 \mathrm{mM}$ potassium phosphate $\mathrm{pH} 7.4,1 \mathrm{M}$ sodium chloride, $1 \mathrm{mM}$ PMSF, $1.5 \%$ (w/v) PVPP and 10\% glycerol. The mixture was homogenized with a Polytron and allowed to stand on ice for 20 min with occasional vortexing every $5 \mathrm{~min}$. After centrifugation at $15.000 \mathrm{~g}$ for $20 \mathrm{~min}$ at $4{ }^{\circ} \mathrm{C}$, the supernatant was recovered and assayed for enzyme activity. Protein extraction of the soluble and particulate fractions was performed as previously described (Sanmartin et al., 2003). Soluble and particulate fractions were assayed directly for AO activity (Diallinas et al., 1997). One unit of AO activity was defined as the oxidation of $1 \mu \mathrm{mol} \mathrm{AA} \mathrm{min}{ }^{-1}$ at $25^{\circ} \mathrm{C}$ considering an extinction coefficient for ascorbic acid of 9.249 $\mathrm{mM}^{-1} \mathrm{~cm}^{-1}$ at $265 \mathrm{~nm}$. All enzyme assays were carried out at $25^{\circ} \mathrm{C}$.

Plasma membranes were isolated in an aqueous two-phase system as described (Kjellbom and Larsson, 1984) with some modifications. In brief, melon fruit tissue was homogenized using Polytron PT10/35 homogenizer, in a medium containing $0.5 \mathrm{M}$ sucrose, $5 \mathrm{mM}$ ascorbic acid, $1 \mathrm{mM}$ PMSF and $10 \mathrm{mM}$ HEPES-KOH pH 7.5. Homogenate was filtered through four layers of cheesecloth and centrifuged for $10 \mathrm{~min}$ at $10.000 \mathrm{~g}$. Supernatant was re-centrifuged for $60 \mathrm{~min}$ at $87.000 \mathrm{~g}$ (Beckman L7-55, SW28 rotor). Resulting pellets were suspended in a phase buffer ( $5 \mathrm{mM}$ potassium phosphate $\mathrm{pH} 7.8,3 \mathrm{mM} \mathrm{KCl}, 0.33 \mathrm{M}$ sucrose) and separated in a $6.5 \%(\mathrm{w} / \mathrm{w})$ two-phase system $(6.5 \%$ PEG 3350, 6.5\% Dextran T400, 0.33 M sucrose, $3 \mathrm{mM} \mathrm{KCl,} 5 \mathrm{mM}$ potassium phosphate $\mathrm{pH} 7.8$ ). The final upper phase was diluted 10 -fold in washing buffer (0.25 M sucrose in HEPES-KOH, pH 7.5) and pelleted at $104.000 \mathrm{~g}$ for $120 \mathrm{~min}$. Final plasma membrane pellets were suspended in membrane resuspension medium $(0.25 \mathrm{M}$ sucrose, $10 \%$ glycerol, $10 \mathrm{mM}$ HEPES-KOH, $\mathrm{pH} 7.5$ ) and stored at $-70{ }^{\circ} \mathrm{C}$ until use. PM $\mathrm{H}^{+}$-ATPase activity in plasma membrane preparations was assayed by spectrophotometric determination of Pi released from ATP hydrolysis as previously described (Terry and Williams, 2002).

\subsection{Analysis of ascorbic acid content}

Total ascorbate was determined following extraction of $500 \mathrm{mg}$ fruit tissue in $2 \mathrm{ml}$ of ice-cold $6 \%(\mathrm{w} / \mathrm{v})$ metaphosphoric acid containing 0.2 mM DTPA. Extracts were centrifuged at $10.000 \mathrm{~g}$ for $4 \mathrm{~min}$ at $4{ }^{\circ} \mathrm{C}$ and the supernatant recovered. For apoplastic content (AWF), thin fruit layers $(500 \mathrm{mg}$ ) were vacuum infiltrated with $66 \mathrm{mM}$ potassium phosphate ( $\mathrm{pH} 3.0), 0.2 \mathrm{mM}$ DTPA and $1 \mathrm{mM}$ sodium azide. AWF was recovered into $100 \mu \mathrm{l}$ of cold $6 \%(\mathrm{w} / \mathrm{v})$ metaphosphoric acid and $0.2 \mathrm{mM}$ DTPA after centrifugation for $10 \mathrm{~min}$ at $5.000 \mathrm{~g}$ at $4{ }^{\circ} \mathrm{C}$, and then tissues were re-weighed in order to determine the volume of recovered AWF.

Ascorbic acid/dehydroascorbate (AA/DHA) content was determined using the spectrophotometric method described by Takahama and Oniki (1992), based upon the difference in absorbance at $265 \mathrm{~nm}$ before, and $3 \mathrm{~min}$ after the addition of $\mathrm{AO}(1 \mathrm{U} / \mu \mathrm{l})$ to a $50 \mu \mathrm{l}$ aliquot of extract in 60 $\mathrm{mM}$ potassium phosphate buffer ( $\mathrm{pH}$ 6.3). Dehydroascorbate content was determined by measuring absorbance before and $5 \mathrm{~min}$ after adding $0.5 \mathrm{M}$ DTT to a separate $50 \mu \mathrm{l}$ aliquot of extract.

Cytosolic contamination of apoplastic fluid was monitored by assaying glucose-6-phosphate dehydrogenase (G6PDH) activity as marker (Lyons et al., 1999). The percentage activity with respect to the corresponding soluble symplastic fraction ranged between 0.1 and 2, which indicates a low contamination with intracellular components.

\subsection{Ethylene production rate}

Fruit were placed in sealed $20 \mathrm{~L}$ glass jars for $30 \mathrm{~min}$ and air samples were taken for ethylene determination. Ethylene concentration was determined by injecting the gas sample into a Varian 3300 gas chromatograph (Varian Instruments, Walnut Creek, CA) equipped with a flame ionization detector and a stainless column.

\subsection{Firmness and weight determination}

Whole fruit flesh firmness was measured using a Chatillon penetrometer fitted with a $7.9 \mathrm{~mm}$ tip, on two opposite sides after skin removal. Determination of the fruit weight was performed using an electronic scale.

\subsection{Confocal laser scanning microscopy}

In order to visualize cell walls, propidium iodide staining was used as a $10 \mu \mathrm{g} / \mathrm{ml}$ solution in water and tissues were incubated for $5 \mathrm{~min}$ (Truernit and Haseloff, 2008). Fluorescence was visualized using a Nikon C1 confocal laser-scanning microscope (CLSM; Nikon D-Eclipse C1; Nikon Inc., Melville, NY, USA) at $536 \mathrm{~nm}$ excitation and $617 \mathrm{~nm}$ emission. Images represent a specific dimension area of melon fruit tissues. Cell number was counted and averaged from 3 cross sections in each one of 3 independent biological replications. Cell size per cross 
A

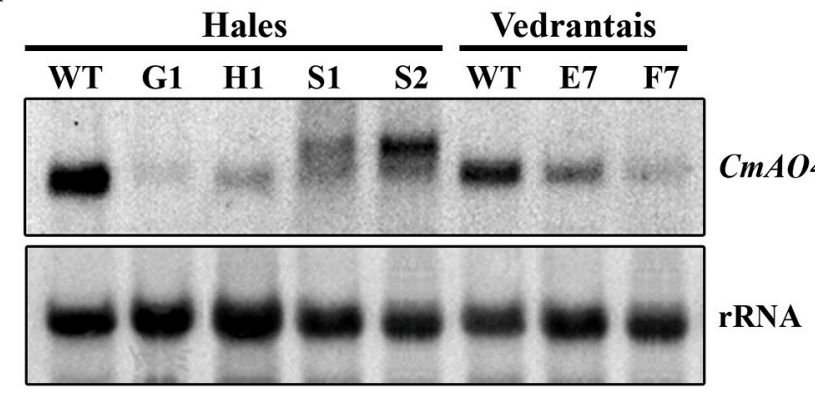

B

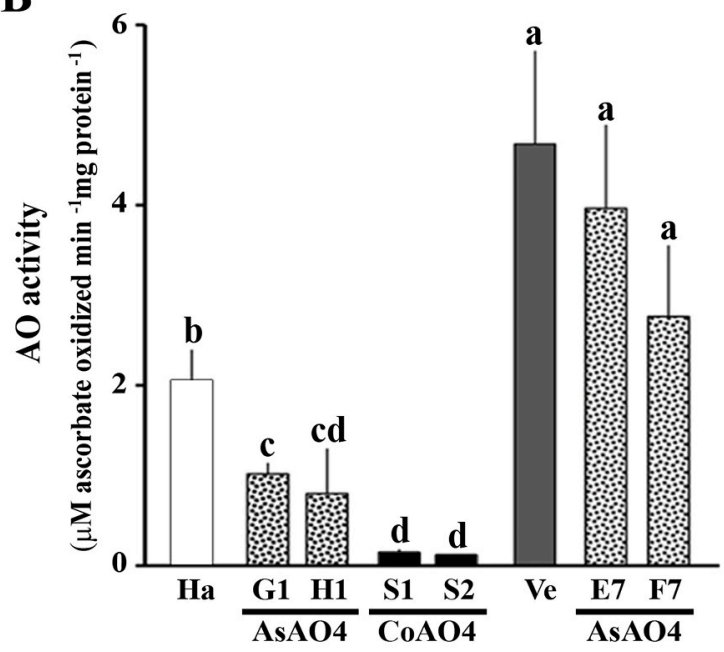

C

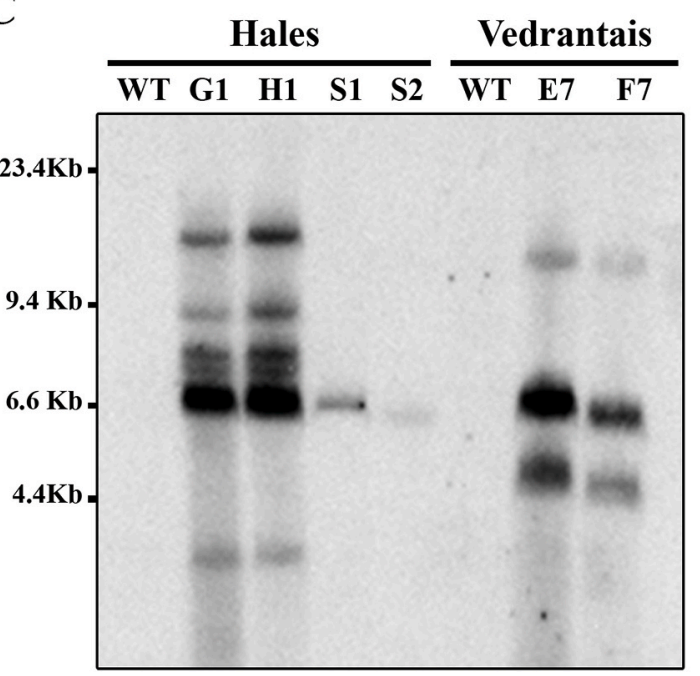

Fig. 1. Characterization of $\mathrm{CmAO4}$ transgenic melon lines. A, Total RNA $(\sim 15 \mu \mathrm{g})$ isolated from WT and T0 transgenic young stems was analyzed by RNA blot with $\mathrm{CmAO4}$ specific probes. Ribosomal RNA staining (rRNA) was used as loading control. B, Total AO specific activity was measured in young stems from WT, AsO4 and $\mathrm{CoAO} 4$ transgenic melon plants. Results represent means from at least three different stems. Vertical bars showed standard deviations. Statistically significant differences are indicated with different letters above the bars. C, Genomic DNA $(\sim 10 \mu \mathrm{g})$ isolated from melon plants was digested with HindIII, fractionated in 0,8\% agarose-TAE gels and hybridized with a NPTII specific probe. Ha, Hales; Ve, Vedrantais; S1, S2, plants transformed with AO4-S construct; G1, H1, E7 and F7, plants transformed with AO4AS construct. section was calculated using the circle area formula $\left(\pi r^{2}\right)$, where $r$ was calculated as the mean between cell maximum and minimum diameter divided by 2. Mean cell size was calculated for each one of the cells of three cross sections of three independent biological replications.

\subsection{Statistical analyses}

Data were analyzed by one way-analysis of variance (ANOVA, Duncan's multiple range test; except for Fig. 1C where Tukey test was applied; $\mathrm{P}<0.05$ ) using the SPSS software.

\section{Results}

\subsection{Generation and evaluation of $\mathrm{CmAO4}$ transgenic lines}

Melon plants exhibit low transformation efficiency. Moreover, efficiency is affected by different factors such as genotype, environmental conditions, Agrobacterium strain and regeneration protocol used (Guis et al., 1998). In our experiments, we used cotyledons as starting plant material, and we determined the regeneration efficiency using different protocols (Supplementary Table 2). Cotyledons from two melon cultivars, Vedrantais and Hales, were transformed with two Agrobacterium tumefaciens strains, C58 and EHA105 both carrying CmAO4 in sense and antisense orientation. Although CmAO1 is mainly expressed in melon fruit, $\mathrm{CmAO4}$ gene, abundant in vegetative tissues, melon ovaries and green immature fruit (Sanmartin et al., 2007) was chosen to possibly target both vegetative and fruit AO expression. Hales explants inoculated with Agrobacterium EHA105 strain showed identical regeneration frequencies at either 175 or $200 \mathrm{mg} / \mathrm{L}$ kanamycin, whereas explants inoculated with C58 strain showed a 2-fold decrease at the higher kanamycin concentration. Shooting frequency was similar on both antibiotic concentrations regardless of the Agrobacterium strain used (Supplementary Table 3). Although both melon genotypes could be transformed with Agrobacterium strain C58, Vedrantais exhibited higher transformation efficiency. In contrast, only Hales transgenic plants could be generated with EHA105 strain. Nine T0 transgenic melon lines, positive for the NPTII Elisa test, were identified out of 13.081 explants used (Supplementary Table 3), however F1 line did not develop further. PCR analysis combined with Southern blotting confirmed the presence of AO4 sense and antisense inserts (Supplementary Fig. 1). Two transgenic plants, originally named S1 and S2, carried the AO4 sense construct while the other seven (B1, E7, F7, H1, G1 and G2) were obtained using the AO-antisense (pAO4-AS) construct. B1 plants showed an aberrant growth and never developed completely, while G2 did not acclimate to greenhouse conditions.

To monitor whether the integration site of the $A O$ sense or antisense constructs, into the melon genome, can influence $\mathrm{CmAO} 4$ transcript accumulation, we performed northern blot using total RNA from young stems (Fig. 1A). CmAO4 transcripts were hardly detected in stems of the G1, H1, E7 and F7 T0 antisense plants (hereafter referred to as AS-AO4 plants), while S1 and S2 T0 transgenic sense lines were almost depleted of $\mathrm{CmAO4}$ transcripts, probably due to co-suppression of the endogenous gene (hereafter referred to as $\mathrm{CoAO} 4$ lines; Fig. 1B). Additionally, AO specific activity was determined in T0 melon transgenic young stems. $\mathrm{AO}$ activity paralleled $\mathrm{CmAO} 4$ transcript levels (Fig. $1 \mathrm{~A}$ and B). Total AO specific activity showed a 2-fold decrease in T0 Hales AS-AO4 plants (G1 and $\mathrm{H} 1$ ), whereas T0 CoAO4 lines (S1 and S2) showed a 95\% reduction in AO specific activity in stems (Fig. 1B). In addition, wild type Vedrantais stems showed higher AO values than Hales counterparts. Moreover, AO activity in Vedrantais AS-AO4 stems (E7 and F7) showed lower levels than wild type (Fig. 1B) but the differences were not statistically significant.

Southern analysis was applied to determine the number of T-DNA insertions in the transgenic lines using the NPTII gene as probe. All transgenic plants carried the NPTII gene, whereas wild type plants did not contain this gene (Fig. 1C). In addition, different copy numbers were 
A

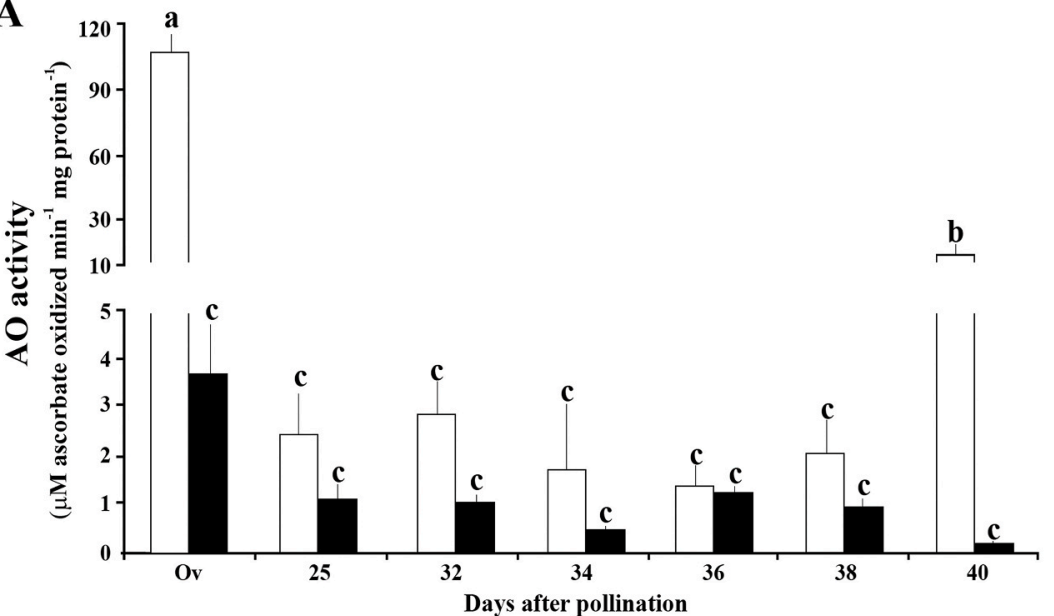

C

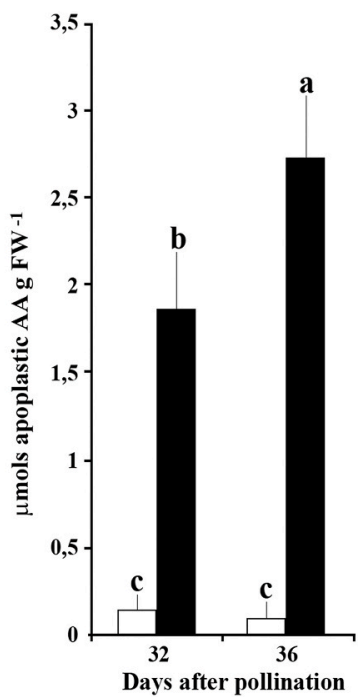

B

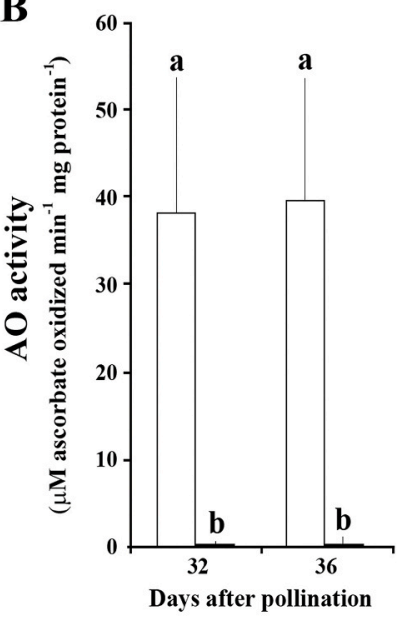

$\mathbf{E}$

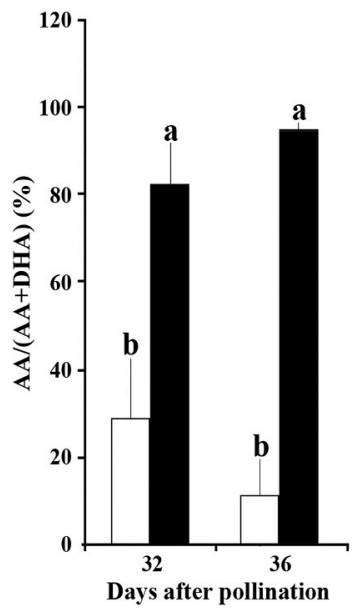

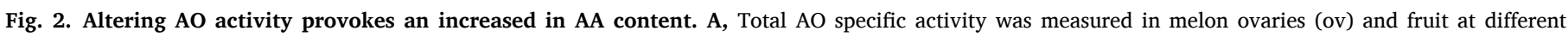

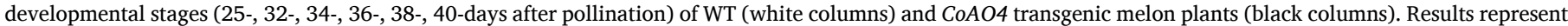

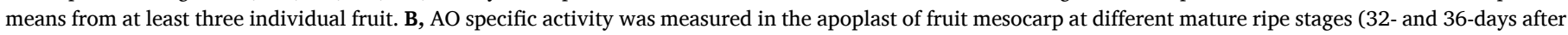

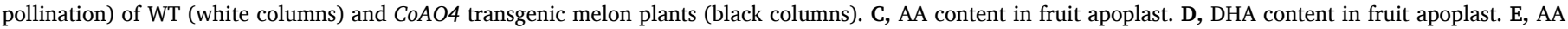

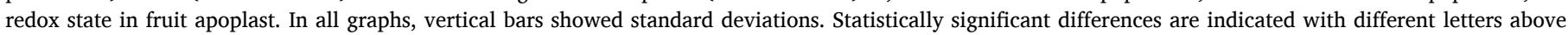
the bars.

detected in the different transgenic plants. Transgenic T0 CoAO4 plants S1 and S2 have a single copy of the T-DNA, while transgenic antisense plants showed multiple copies (Fig. 1C). TO AS-AO4 Hales plants harbored five to six copies whereas transgenic antisense Vedrantais plants presented at least three copies of the T-DNA insertion (Fig. 1C). The similar pattern obtained within each pair of transgenic lines indicated that they could be derived from three different transformation events and that each line was a replicate of each other (S1 to S2, G1 to $\mathrm{H} 1$ and E7 to F7). Taken together, three independent transgenic lines were generated either by antisense or by co-suppressed silencing that showed reduced $\mathrm{CmAO} 4$ transcript accumulation and AO enzymatic activity. Since CoAO4-S2 contained a single copy of the transgene and showed the highest reduction in AO activity, we generated CoAO4-S2 homozygous plants for further characterization.

\subsection{Reduced AO levels increase AA content in melon fruit}

To determine whether alteration of $\mathrm{CmAO4}$ expression levels affected enzyme activity, we measured total $\mathrm{AO}$ activity in different fruit developmental stages (Fig. 2A). AO activity was particularly high in wild type ovaries in line with previous published data (Diallinas et al., 1997), whereas transgenic $\mathrm{COAO} 4$ plants displayed a $97 \%$ reduction compared to wild type plants. During fruit development, $\mathrm{CoAO} 4$ plants showed a substantial reduction in $\mathrm{AO}$ activity, from 50 to $90 \%$ depending on the developmental stage. Ripe fruit (40-DAP), showed a significant increase in AO activity in wild type fruit, which was not observed in the transgenic ones, indicating a reduced AO activity also in fruit of $\mathrm{CoAO} 4$ plants. Since AO is mostly located in the apoplast, AO activity was measured in the cell wall fraction of inner and outer mesocarp areas of ripe fruit, where AO is mostly active (Diallinas et al., 1997). Wild type fruit showed highest AO activity in the cell wall bound fraction of the outer mesocarp areas at the different fruit stages, whereas transgenic CoAO4 fruit exhibited a $90 \%$ reduction in AO activity both in the inner and outer mesocarp areas (Fig. 2B). Together, these data indicate that the reduced $\mathrm{CmAO} 4$ transcript accumulation observed in $\mathrm{CoAO} 4$ plants drives a severe reduction of AO activity in any melon tissue studied.

The observed decrease in AO activity in the transgenic fruit could alter either the AA content and/or the AA redox state. To assess this hypothesis, we measured apoplastic AA content in melon fruit at two developmental stages, mature (32-DAP) and preclimacteric (36-DAP). 
A

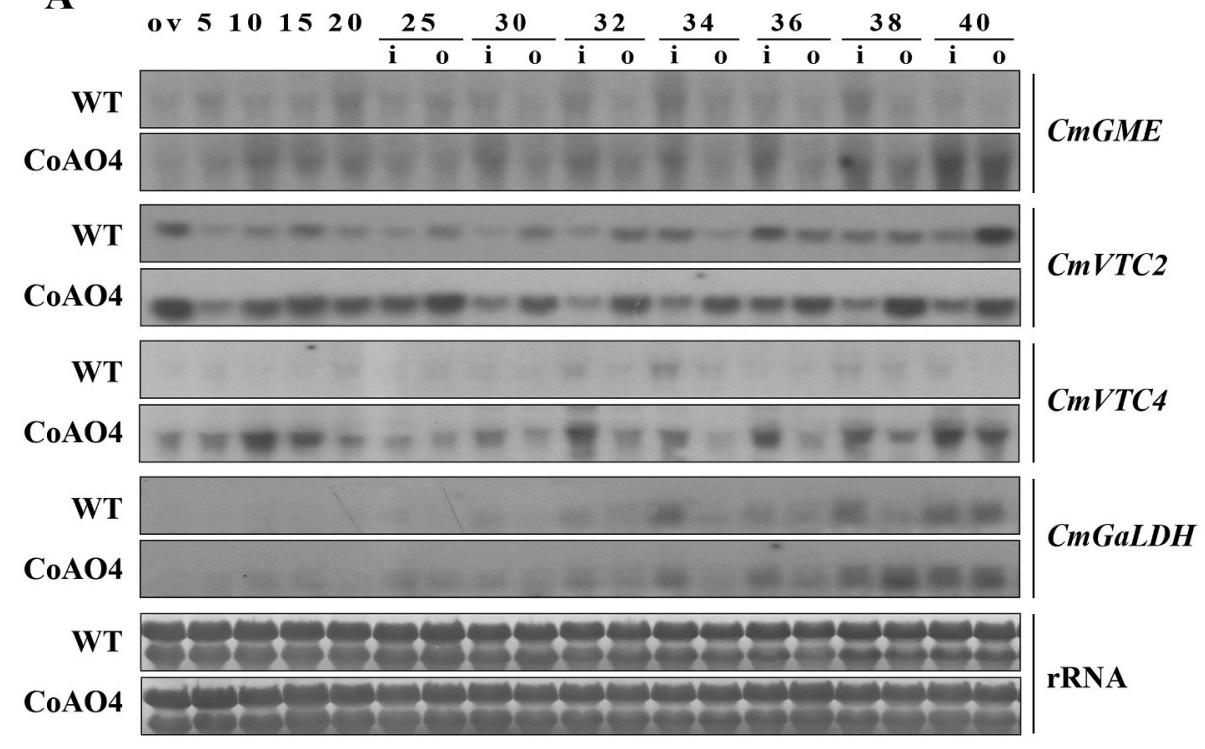

Fig. 3. Reduced AO levels affect AA biosynthetic and recycling genes. A, Expression of CmGME, CmVTC2, CmVTC4 and CmGaLDH genes during fruit development. B, Expression of CmAPX1, CmMDHAR and $C m D H A R$ genes during melon fruit development. Total RNA $(\sim 15 \mu \mathrm{g})$ from melon ovaries (ov) and fruit at different developmental stages (5-, 10-, 15-, 20-, 25-, 30-, 32-, 34-, 36-, 38-, 40-days after pollination) of Hales (WT) and CoAO4 transgenic melon plants was fractionated in denaturing agarose gels, transferred to Hybond N-membranes and hybridized with specific ${ }^{32} \mathrm{P}$-radiolabeled probes. Ribosomal RNA staining (rRNA) was used as loading control. i: inner part of the fruit mesocarp, o: outer part of fruit mesocarp.

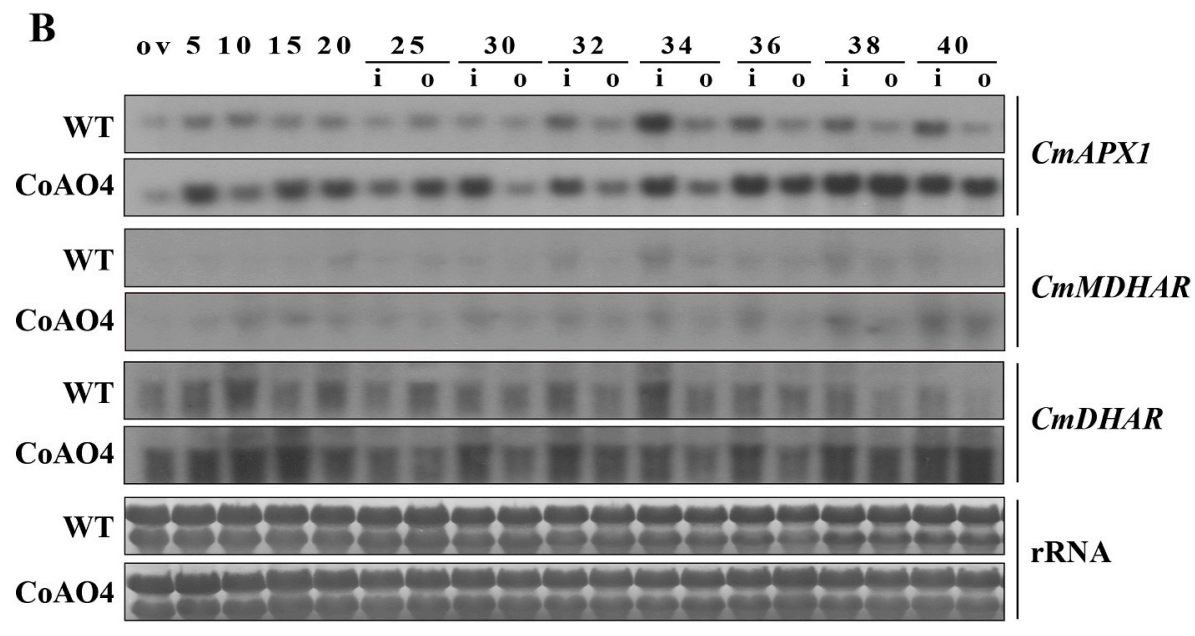

AA content was significantly increased in the apoplast of $\mathrm{CoAO} 4$ fruit, being 13- and 25-fold higher than wild type in mature and preclimacteric transgenic fruit, respectively (Fig. 2C). Moreover, DHA content was particularly low in the apoplast of $\mathrm{CoAO} 4$ preclimacteric fruit, showing an 8-fold decrease compared to wild type levels (Fig. 2D). Consequently, apoplastic redox state, calculated as the ratio of AA to total ascorbate (AA + DHA), was 3- and 8-fold higher in transgenic mature and preclimacteric fruit than wild type, respectively (Fig. 2E). Together, reduction of AO activity seems to modify apoplastic AA redox state via altering both AA and DHA contents in melon fruit.

\subsection{CoAO4 melon fruit exhibit an induction in the expression of $A A$ biosynthetic genes}

The substantial reduction of AO activity and the consequent increase in AA levels in $\mathrm{COAO} 4$ fruit raised the question whether this modification influenced the AA biosynthetic and/or AA recycling pathways (Fig. 3). We first monitored the mRNA accumulation of key genes of the AA biosynthetic pathway during fruit ripening in outer and inner parts of fruit mesocarp (Fig. 3A). GDP-D-mannose 3', $5^{\prime}$-epimerase (GME) mRNA abundance remained relatively constant during wild type fruit ripening, whereas increased slightly in $\mathrm{CoAO} 4$ fruit, especially in the inner mesocarp areas of ripe fruit (38- and 40-DAP; Fig. 3A).
In wild type fruit, GDP-L-galactose phosphorylase (GGP/VTC2) transcripts were clearly detected, mainly in the outer mesocarp of young (25- and 30-DAP) and ripe (40-DAP) fruit, while a substantial GGP/ VTC2 induction was observed in $\mathrm{COAO} 4$ fruit throughout ripening, especially in the outer mesocarp areas. L-galactose-phosphate phosphatase (GPP/VTC4) mRNA levels were dimly detected in wild type fruit but exhibited a significant accumulation in $\mathrm{CoAO} 4$ transgenic ones during fruit development (Fig. 3A). Abundance of GaLDH, the last step in the AA biosynthetic pathway, increased slightly during ripening in both genotypes and exhibited higher expression in the last stages (38and 40-DAP). Transcript accumulation of the AA recycling genes was slightly higher in transgenic fruit during ripening (Fig. 3B); in particular $D H A R$ and APX1 exhibited a substantial higher mRNA abundance in transgenic fruit during all stages of maturation (Fig. 3B), while MDHAR did not show critical differences. Collectively, the expression of most of the AA biosynthetic and recycling genes studied herein was induced in melon transgenic fruit and, together with $A O$ co-suppression, they might contribute to the observed enhanced AA content.

\subsection{Ripening pattern is modified in transgenic CoAO4 fruit}

Melon as a climacteric fruit is characterized by increased ethylene production rates and a rise in cellular respiration during ripening. To 
$\mathbf{A}$

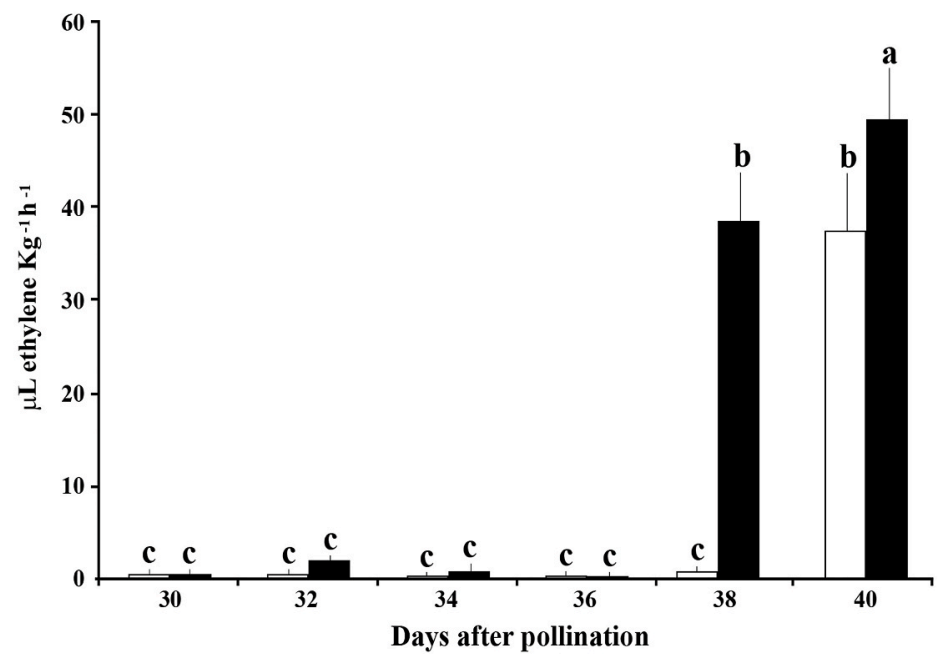

B

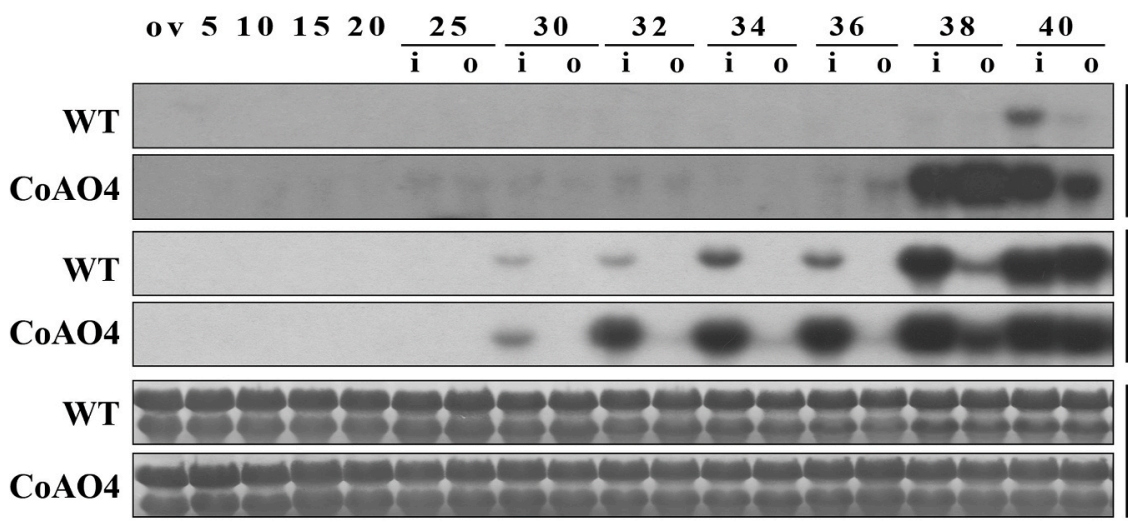

Fig. 4. Reduced AO activity provoked altered ripening features. A, Ethylene emission rates from fruit at different development and ripening stages (30-, 32-, 34-, 36-, 38-, 40-days after pollination) of WT (white columns) and $\mathrm{CoAO} 4$ transgenic melon plants (black columns). Vertical bars show standard deviations. Statistically significant differences are indicated with different letters above the bars. B, CmACO and $C m A A T 1$ gene expression during melon fruit development and ripening. Total RNA $(\sim 15 \mu \mathrm{g})$ from melon ovaries (ov) and fruit at different developmental stages (5-, 10-, 15-, 20-, 25-, 30-, 32-, 34-, 36-, 38-, 40-days after pollination) of Hales (WT) and CoAO4 transgenic melon plants was fractionated in denaturing agarose gels and hybridized with specific ${ }^{32}$ P-radiolabeled probes. Ribosomal RNA staining (rRNA) was used as loading control. i: inner part of the fruit mesocarp, o: outer part of fruit mesocarp. C, ACO activity during fruit development. Fruit at different ripening stages (30-, 32-, 34-, 36-days after pollination) of WT (white columns) and CoAO4 transgenic melon plants (black columns) were used. Vertical bars show standard deviations. Statistically significant differences are indicated with different letters above the bars.

\section{CmAAT1}

rRNA

C

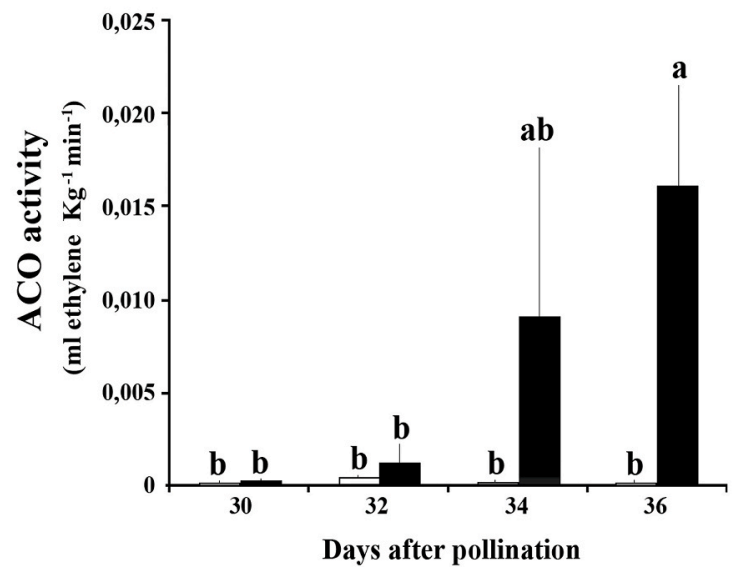

study whether altered $\mathrm{AO}$ and AA levels can affect the ripening process in melon fruit, we measured emission of ethylene throughout fruit ripening, and examined the transcript levels and activity of ethylene biosynthesis related enzymes. Altering the AA content and thus the redox state seems to provoke an earlier and a higher ethylene production in transgenic ripe fruit compared to wild type fruit (Fig. 4A), which paralleled a corresponding behavior of 1-aminocyclopropane-1-carboxylic acid oxidase (ACO) mRNA steady state levels and ACO enzymatic activity (Fig. 4B and C).

To establish if other ripening traits were affected, we monitored the expression of an alcohol acyl-transferase, AAT1, an ethylene regulated gene that plays a key role in the biosynthesis of ester volatiles and contributes to the aroma properties of ripe melon fruit (El-Sharkawy et al., 2005). AAT1 transcripts followed the same pattern of ACO mRNAs induction and ethylene production during ripening (Fig. 4B). Although AAT1 mRNA was detected at the same developmental stage in wild type and in $\mathrm{COAO} 4$ fruit, its accumulation was significantly higher in the latter.

Flesh firmness is a reliable indicator of fruit maturity. Increase in the AA levels or redox status caused a progressive loss in fruit firmness, 


\section{A}

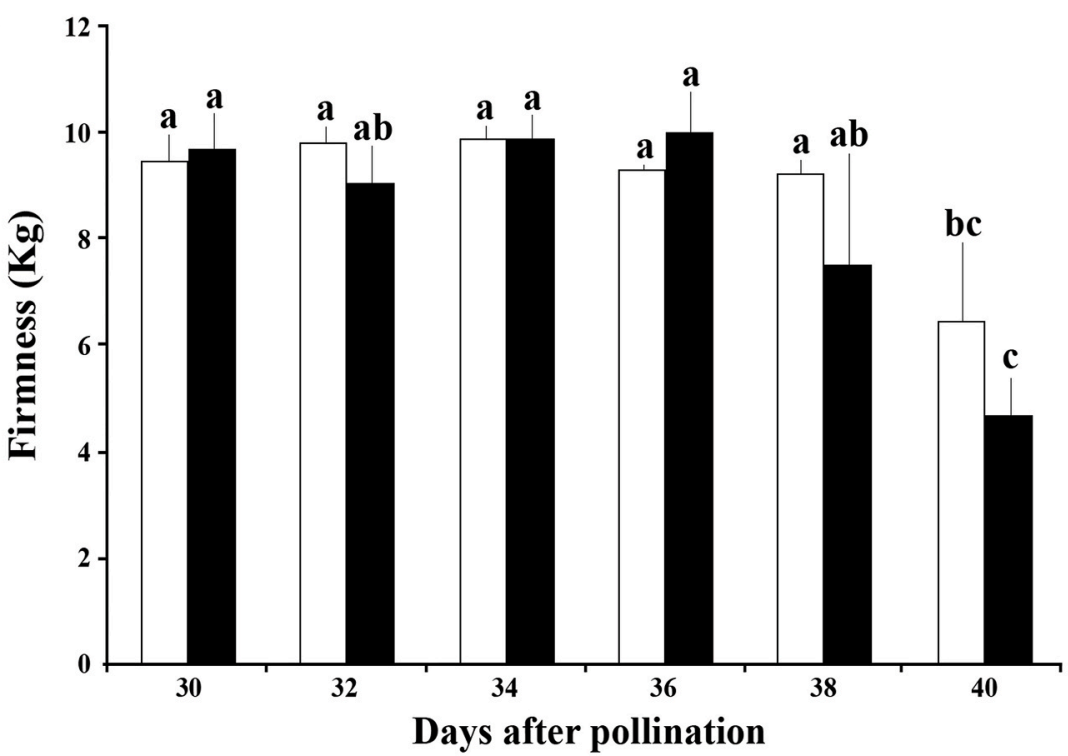

B

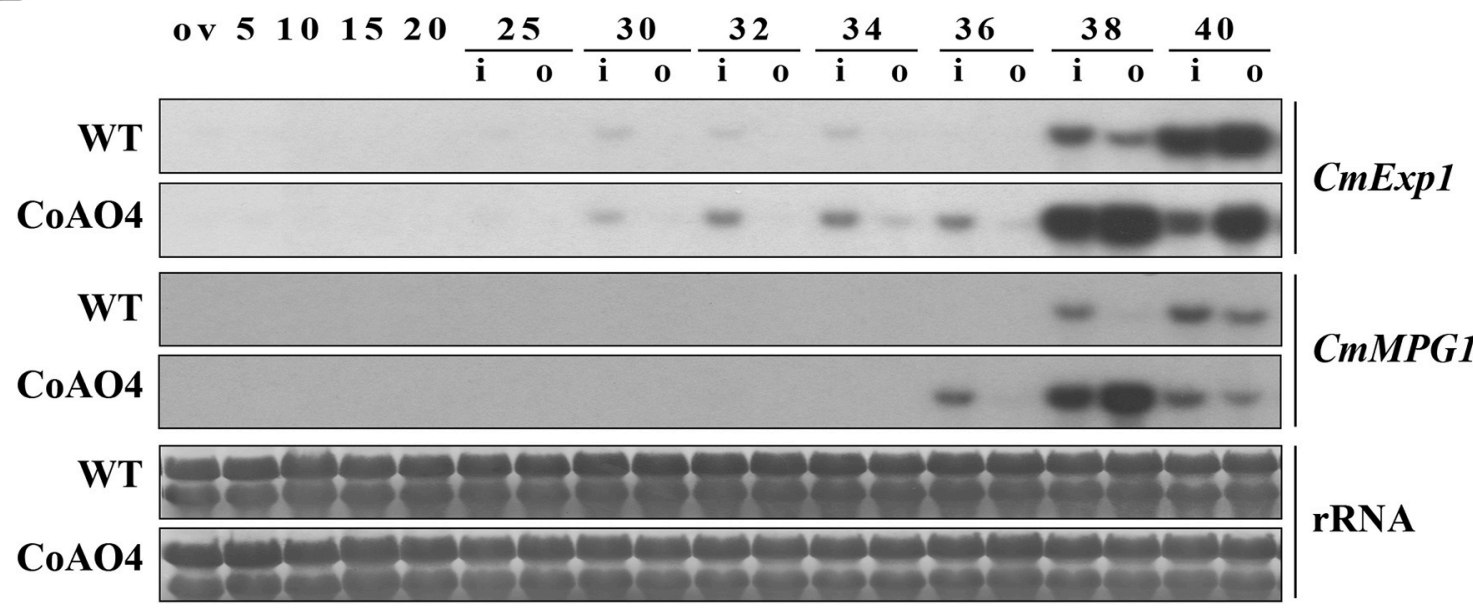

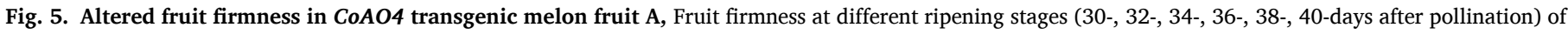

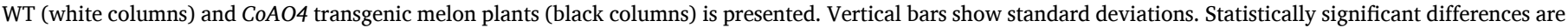

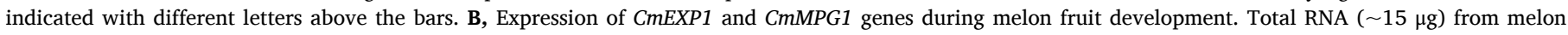

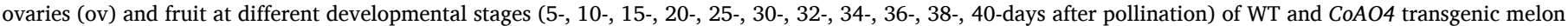

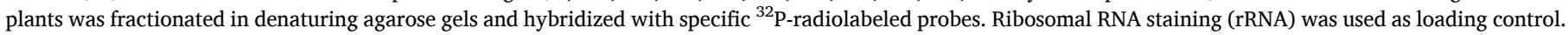
i: inner part of the fruit mesocarp o: outer part of fruit mesocarp.

which was more evident in overripe fruit (40-DAP) (Fig. 5A). To get a better insight in the cell wall changes, we studied the expression of the cell wall modifying genes, expansin (Exp1) and polygalacturonase (MPG1) during melon fruit development and ripening. Expression of both genes appeared earlier and was more intense in transgenic CoAO4 fruit than in wild type (Fig. 5B), similarly to the pattern of fruit firmness alteration. Taken together, all ripening physiological, physical and biochemical features studied were altered in $\mathrm{CoAO} 4$ fruit, thus it appears that lowering $\mathrm{AO}$ levels provoke a faster and premature ripening in these transgenic melon fruit.

\subsection{Silencing of AO provokes a significant reduction in fruit size}

In addition to the changes observed in AA metabolism and in the ripening process, a clear effect was observed on weight and size of transgenic CoAO4 fruit (Fig. 6A and B). Growth of transgenic CoAO4 fruit was arrested at 32-DAP causing a significant reduction of weight in 36- to 40-DAP fruit compared to wild type (Fig. 6A and B). However, no differences between wild type and $\mathrm{CoAO} 4$ were observed during vegetative growth or in early developmental stages until 32-DAP.

The above observation led us to question whether the differences in fruit size and weight could be linked to alterations in cell number (cell division) and/or size (cell expansion) of the fruit cells, a fact that potentially could lead to the suggested link of AO function with cell growth (Pignocchi et al., 2003b). To verify this possibility, cells from inner and outer mesocarp areas of wild type and transgenic CoAO4 fruit at 36-DAP were analyzed by confocal microscopy (Fig. 6B). This experiment was conducted in different year with higher summer temperatures that caused an earlier ripening, thus both genotypes reached their maximum size on 36-DAP. Transgenic ripe CoAO4 fruit exhibited a greater number of cells (Fig. 6B and C), which concomitantly had smaller size both in inner and outer mesocarp areas (Fig. 6D). Taking into consideration the above results and the theories regarding AO involvement in cell-wall loosening and apoplast acidification, we hypothesized that AO may participate in cell expansion of melon fruit. This function could be related to transport processes through the plasma 
A

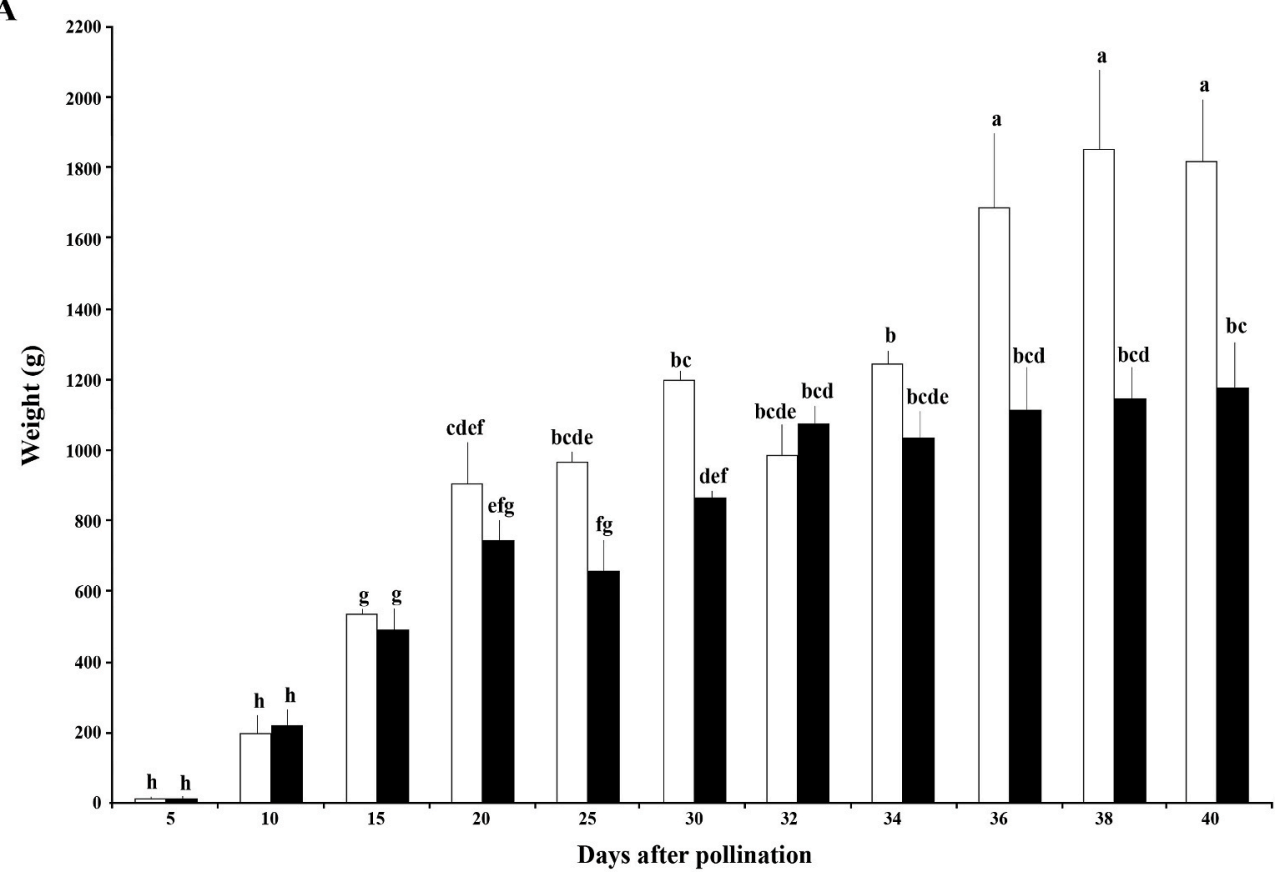

Fig. 6. Effect of AO modification on fruit growth. A, Fruit of WT (white columns) and CoAO4 transgenic melons (black columns) were weighted at different developmental stages. B, Fruit photographs of WT and CoAO4 transgenic melons and representative confocal images of melon fruit mesocarp cross sections stained with propidium iodine. C-D, Fruit of the same developmental stages used to determine cell number per cross section (C) and cell area (D). E, PM $\mathrm{H}^{+}$-ATPase activity in WT (white columns) and CoAO4 transgenic plants (black columns) 34 days after pollination in inner and outer mesocarp. Vertical bars show standard deviations. Statistically significant differences are indicated with different letters above the bars.
B
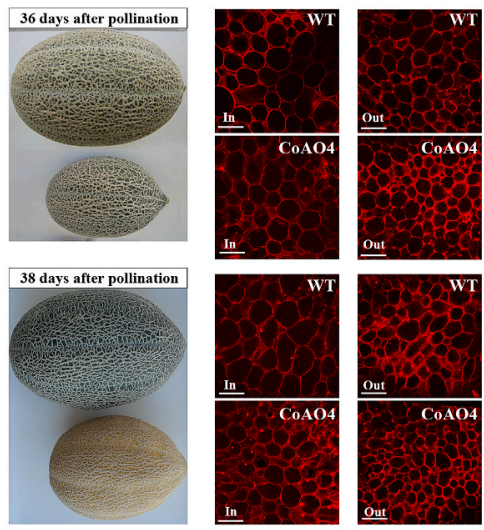

D

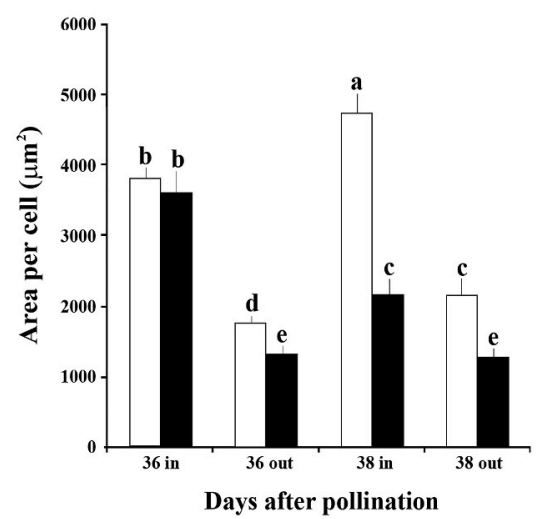

C

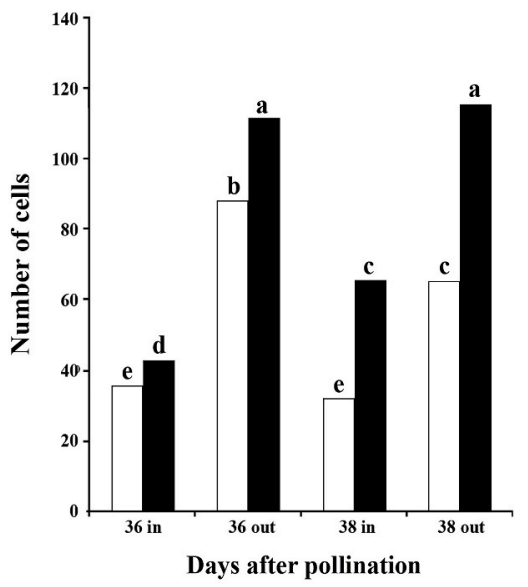

$\mathbf{E}$

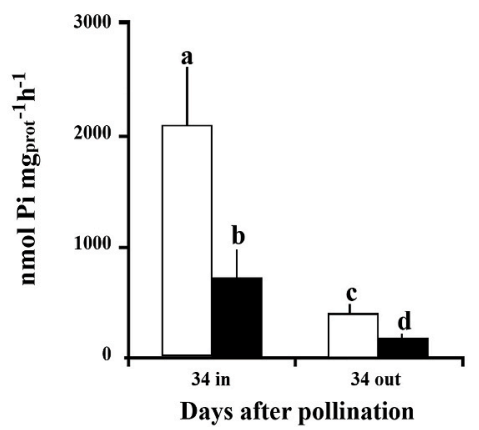

membrane via the stimulation of $\mathrm{H}^{+}$-ATPase activity (Gonzalez-Reyes et al., 1994; Kato and Esaka, 2000; Smirnoff, 1996, 2000). Therefore, $\mathrm{PM} \mathrm{H}^{+}$-ATPase activity was evaluated in isolated plasma membranes at inner and outer mesocarp areas from wild type and transgenic fruit at a developmental stage before the cell size reduction was observed, 34-DAP. CoAO4 fruit, both in inner and in outer regions showed lower
PM $\mathrm{H}^{+}$-ATPase activity at this developmental stage when compared to wild type fruit (Fig. 6E). Indeed, the $\mathrm{PM} \mathrm{H}^{+}$-ATPase activity was about $85 \%$ and $70 \%$ less at inner and outer areas in transgenic fruit, respectively. Taken together, characterization of melon $\mathrm{CoAO} 4$ reveals a substantial AO participation in the rapid fruit growth typical of cucurbits, and further points out an alternative route for increasing AA content in 
ripening fruit.

\section{Discussion}

Melons have low to medium AA content, ranging from 10 to $35 \mathrm{mg}$ / $100 \mathrm{~g}$ FW depending on morphotypes and varieties (Davey et al., 2000; Fenech et al., 2018; Mellidou et al., 2017). Despite its importance in global fruit production (over 30 million tons according to FAOSTAT), only a limited number of studies focus on the genetic manipulation of melon AA levels, and only a single AA-related QTL has been mapped on LG 5 in melon (Park et al., 2009). Therefore, the existence of different types of fruit together with the high diversity in AA content between cultivated varieties indicates that there is a great potential for improving AA levels in melon fruit. In this study, suppression of $A O$ activity was used as an alternative route for AA bio-fortification in melon (Mellidou et al., 2017; Mellidou and Kanellis, 2017). The reduced AO activity in the $\mathrm{CoAO} 4$ plants has led to a dramatic increase in the apoplastic AA content in melon fruit with a concomitant increase in the AA redox state in the apoplast. The observed correlation between low $A O$ activity and high AA levels agrees with previous reports in tomato fruit (Abdelgawad et al., 2019; Zhang et al., 2011) and tobacco (Pignocchi et al., 2003b).

The AA pool size is regulated by the fine orchestration of biosynthesis, recycling, transport, compartmentalization and oxidation (Mellidou and Kanellis, 2017). In this regard, the changes observed in AO activity of the transgenic plants, as well as AA content and redox state, were also mirrored in alterations in transcript levels of AA biosynthetic and recycling genes. In particular, the transcript levels of CmVTC2 and CmVTC4 of melon fruit at the later stages of ripening were significantly higher in $\mathrm{CoAO} 4$ transgenic plants compared to wild type plants, although the expression pattern during ripening showed some similarities. The increased expression of these two genes also correlated with the high levels of AA accumulation in ripe fruit, suggesting that these genes are key determinants in controlling AA biosynthesis, as previously suggested in tomato (Ioannidi et al., 2009; Mellidou et al., 2012a), kiwi (Bulley and Laing, 2016) or apple (Mellidou et al., 2012b). A less pronounced increase for CmGME and $\mathrm{CmGalDH}$ was observed in transgenic ripening fruit. Thus, lowering apoplastic AO activity might provoke a feed-forward amplification loop of the $\mathrm{L}_{\mathrm{L}}$-galactose biosynthetic pathway, which might further contribute to the enhancement of the AA pool size within the cells. In addition, a substantial induction of both CmAPX1 and CmDHAR mRNA transcripts, and to a lesser extent of CmMDHAR, was recorded in transgenic ripe fruit compared to wild type ones, that might further contribute to the enhanced apoplastic and cellular AA content. The diverse effect of MDHAR and DHAR in governing fruit AA pool size has been demonstrated in different fruit species, using either QTL mapping (Mellidou et al., 2012b; Stevens et al., 2007, 2008), or gene expression analysis (Mellidou et al., 2012a). Induction of AA recycling pathway at the absence of $\mathrm{AO}$ activity pinpoints a feedback regulatory mechanism of AA pool size.

Previous studies have proposed that $A O$ transcript levels are high during early fruit development in tomato, presumably due to its role in cell expansion, and then decline in ripe fruit (Ioannidi et al., 2009). By contrast, as reported herein and from other studies in melon (Diallinas et al., 1997; Moser and Kanellis, 1994; Sanmartin et al., 2007), AO expression and activity is very high in ovaries, and declines dramatically in young developing fruit followed by a transient increase in the outer mesocarp areas of ripe fruit in wild type plants. This finding probably highlights distinct roles of this enzyme in different species during the ripening process. AA is an essential molecule in ethylene production as it serves as a co-factor for the enzymatic activity of 1-aminocyclopropane-1-carboxylic acid oxidase (ACO), which catalyzes the last step of ethylene biosynthesis. In this regard, most studies have focused on the ethylene-mediated regulation of AA pool size during fruit ripening, and not vice-versa. Recently, ethylene has been found to regulate AA biosynthesis via ETHYLENE-INSENSITIVE3 (EIN3) and ABA INSENSITIVE4 (ABI4) in Arabidopsis plants, by the transcriptional repression of
VTC2 (Yu et al., 2019). Our study demonstrates that increased AA through down-regulation of AO activity can trigger an early induction of ethylene production in the transgenic fruit compared to wild-type. This is further correlated with the enhanced ACO expression and activity at the later stages of ripening. Thus, our results support that ethylene, as a key regulatory player of ripening, is transcriptionally and antagonistically modulated by $A O$. The cross-talk between decreased AO activity and high ethylene production can be partly explained by the enhanced availability of AA supplying $\mathrm{H}^{+}$to ACC in the reaction catalyzed by ACO (De Tullio, 2020) or by the alteration in the redox mediated signaling within the apoplast, as AA acts as a signaling molecule itself, independently of oxidative stimuli (Foyer et al., 2020). Another ripening-related trait, which seemed to be affected by the suppression of $A O$ in melon is an alcohol acyl-transferase, AAT1, which contributes to the synthesis of volatile esters that mostly contribute to the characteristic aroma of the fruit (El-Sharkawy et al., 2005; Galaz et al., 2013). Our findings demonstrated that the expression of $A A T 1$ was significantly upregulated by $A O$ reduction during ripening, probably as a result of the increased ethylene production rate.

Softening of melon fruit might be caused by the loss of hypodermal mesocarp membrane integrity (Lester and Stein, 1993). Extensive research has addressed the cell wall alterations that occur in ripening melon, indicating that cell-wall disassembly is characterized by the dismantling and re-organization of various polysaccharide networks by diverse families of wall-modifying proteins, including expansins and polygalacturonases (Nishiyama et al., 2007; Rose et al., 1998). Current knowledge on the ripening-mediated softening suggests that this process is finely regulated by alterations in pectic and hemicellulosic polysaccharides, and this process is of vital importance for the determination of commercial value of fruit crops (Wang et al., 2018). Nevertheless, it is still unclear whether this process is completely or partially hormonal regulated, whereas the involvement of AO in cell wall modifications during ripening remains largely untapped. Transgenic $\mathrm{CoAO} 4$ fruit were less firm than wild type fruit, evidencing a putative function for AO in melon fruit softening. Loss of firmness was also correlated with an earlier and increased ethylene production, as well as higher transcript levels of the cell-wall modifying genes, CmEXP1 and CmMPG1. Transgenic melon with reduced $A C O$ expression has been previously shown to exert a delayed but reduced flesh firmness (Flores et al., 2001), suggesting that softening is completely or partially ethylene regulated in melon fruit. Another possible explanation for the loss of firmness in $\mathrm{CoAO} 4$ fruit can be attributed to DHA, which is significantly reduced in transgenic fruit during ripening. It has been previously suggested that DHA is mostly responsible for the cell-wall loosening, either by preventing wall protein covalent cross-linking and interactions with pectin, or by actively removing calcium from cell wall by enhancing oxalate formation, resulting in a less rigid structure due to the removal of calcium from cell wall (Al-Madhoun et al., 2003; Lin and Varner, 1991). Furthermore, DHA and MDHA may facilitate vacuolation and cell-wall loosening by controlling the redox state over the cell cycle (Garchery et al., 2013). Taken together, these results support the hypothesis that $\mathrm{AO}$ has a direct function in fruit softening in an ethylene-dependent manner, although other ethylene-independent modes of action may also influence this complex process.

Studies on Cucurbitaceae and Solanaceae species reinforce the hypothesis that $\mathrm{AO}$ participates in cell expansion, as it is primarily expressed and is highly active in fast growing tissues, such as ovaries, and green immature fruit (Al-Madhoun et al., 2003; Diallinas et al., 1997; Fotopoulos et al., 2006; Pignocchi et al., 2003b; Sanmartin et al., 2007; Yamamoto et al., 2005), whereas its mode of action can vary in a species-dependent manner. AO has been mostly correlated with cell expansion early in fruit development (Kato and Esaka, 2000). However, silencing of $A O$ in melon also indicates an $\mathrm{AO}$ role at later developmental stages, since a decrease in fruit size was observed in transgenic CoAO4 ripe fruit compared to wild type. AO-mediated oxidation of AA produces MDHA, which is able to accept electrons from the plasma membrane 
A

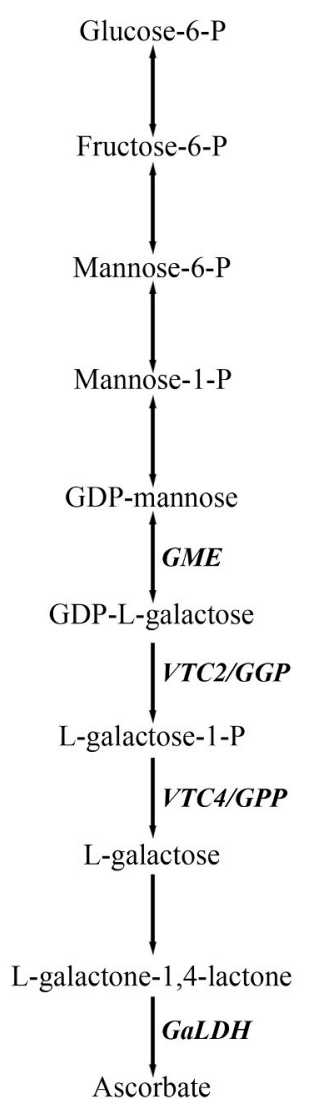

B

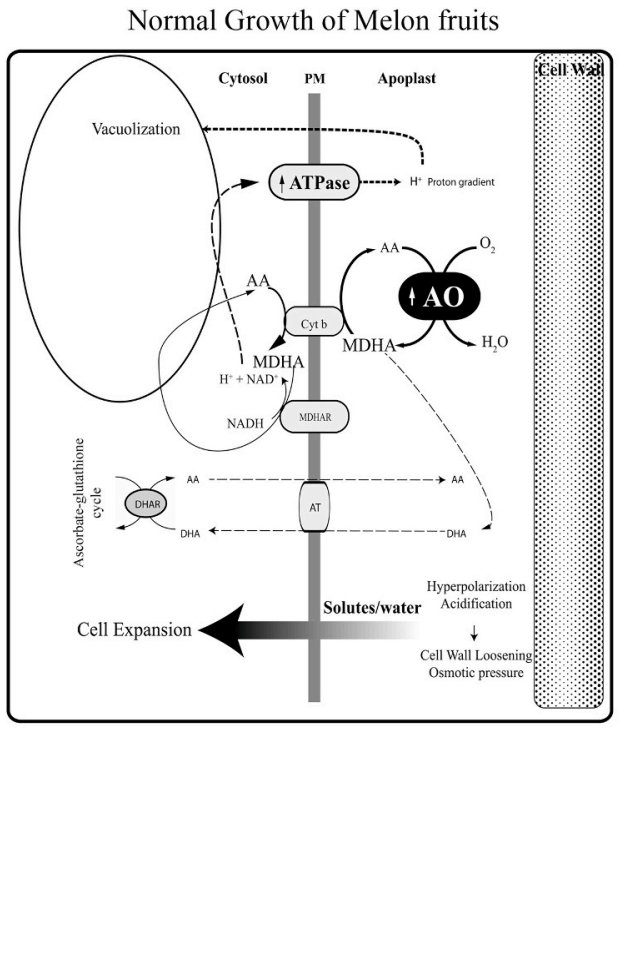

C

Suppressed Growth in $\mathrm{COAO} 4$ fruits

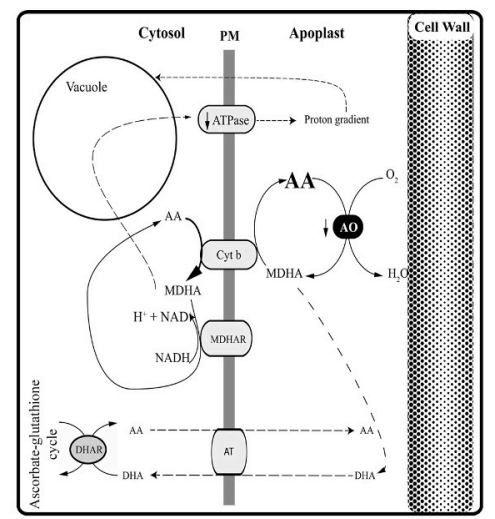

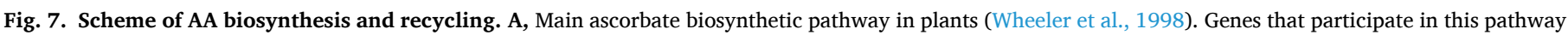

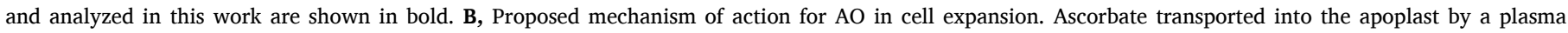

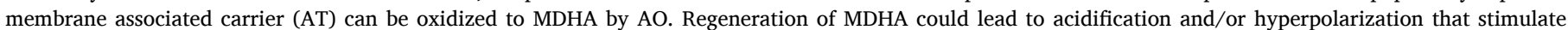

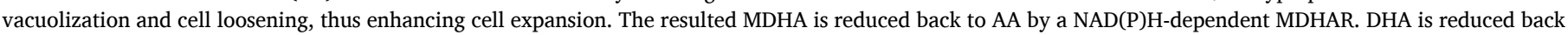

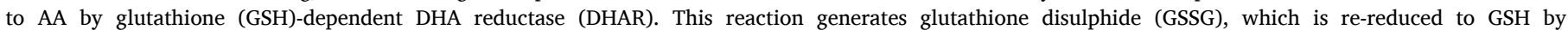

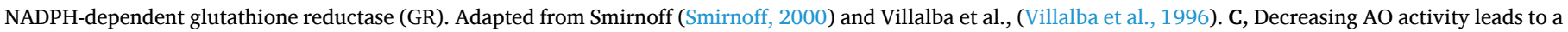

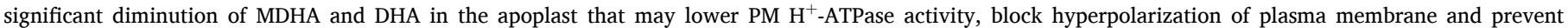
cytoplasm and vacuole expansion. Consequently, fruit showed a decreased growth, with smaller fruit cell size.

redox system to regenerate $\mathrm{AA}$ in the ascorbate/glutathione cycle (Davey et al., 2000) In this case, the plasmalemma becomes hyperpolarized and a PM H $\mathrm{H}^{+-}$ATPase is activated causing the acidification of the apoplast and activation of solute transport to cytoplasm (Gonzalez-Reyes et al., 1994). This mode of action can change the osmotic pressure causing transport of water into the cytoplasm and the vacuole, and thus cell expansion. $A O$ silencing provokes a significant diminution of MDHA and DHA in the apoplast that may deactivate $\mathrm{PM} \mathrm{H}^{+}$-ATPase (Ferjani et al., 2013) and block hyperpolarization of plasma membrane, thus preventing vacuolization and cell expansion (Fig. 7). The proposed mechanism is supported by the decreased growth, smaller cell size in the mesocarp and decreased PM H ${ }^{+}$-ATPase activity observed in the transgenic fruit. Thus, this is an in vivo evidence of the involvement of $\mathrm{AO}$ in cell expansion and consequently in the fast growth of cucurbits.

\section{Conclusion}

Our findings offer novel insights into the function of AO enzyme in melon plant. It is evident that fruit with lower AO activity not only have higher AA levels, but also exhibit an earlier induction of ripening via enhanced ethylene production, as well as smaller fruit size, accompanied by a greater number of cells and a smaller cell size. This work provides some further clues on the fine orchestration between AA oxidation and recycling in the apoplast that also implicates a crosstalk with ethylene. Taken together, our results reinforce the proposed model for the in vivo AO participation in the rapid fruit growth of melon, and further point at intriguing aspects of fruit AA enhancement via the alternative route of decreasing AA catabolism that merits further exploration.

\section{Authors contribution}

AKK and MS perceived and designed the work, FC, MS, AK, GT, MSK, SV-J, TCA, SK, PT, performed the experiments, IP supervised the molecular analyses, RG supervised melon transformation, FC, MS, IM, IP and AKK designed and wrote the manuscript. All authors read and approved the manuscript.

\section{Declaration of competing interest}

The authors declare that they have no known competing financial interests or personal relationships that could have appeared to influence the work reported in this paper.

\section{Acknowledgements}

This research was financially supported by grants co-funded by the European Social Fund \& Greek National Resources-EPEAEK IIPYTHAGORAS/319, and Synergasia- GR-NUTRITOM/11Syn_3_480. We thank COST ACTION FA1106/QUALITY FRUIT. 
Appendix A. Supplementary data

Supplementary data to this article can be found online at https://doi. org/10.1016/j.plaphy.2020.08.040.

\section{References}

Abdelgawad, K.F., El-Mogy, M.M., Mohamed, M.I.A., Garchery, C., Stevens, R.G., 2019. Increasing ascorbic acid content and salinity tolerance of cherry tomato plants by suppressed expression of the ascorbate oxidase genes. Agronomy-Basel 9.

Al-Madhoun, A.S., Sanmartin, M., Kanellis, A.K., 2003. Expression of ascorbate oxidase isoenzymes in cucurbits and during development and ripening of melon fruit. Postharvest Biol. Technol. 27, 137-146.

An, G., Ebert, P.R., Mitra, A., Ha, S.B., 1988. Binary vectors. Plant Molecular Biology Manual. Kluwer Academic Publishers, Dordrecht, Belgium.

Arrigoni, O., De Gara, L., Tommasi, F., Liso, R., 1992. Changes in the ascorbate system during seed development of Vicia faba L. Plant Physiol 99, 235-238.

Arrigoni, O., Calabrese, G., De Gara, L., Bitonti, M.B., Liso, R., 1997. Correlation between changes in cell ascorbate and growth of Lupinus albus seedlings. J. Plant Physiol. 150, 302-308.

Bellini, E., De Tullio, M.C., 2019. Ascorbic Acid and Ozone: Novel Perspectives to Explain an Elusive Relationship, Plants, p. 8. Basel.

Bulley, S., Laing, W., 2016. The regulation of ascorbate biosynthesis. Curr. Opin. Plant Biol. 33, 15-22.

Conklin, P.L., Williams, E.H., Last, R.L., 1996. Environmental stress sensitivity of an ascorbic acid-deficient Arabidopsis mutant. Proc. Natl. Acad. Sci. U. S. A. 93, 9970-9974.

Conklin, P.L., Saracco, S.A., Norris, S.R., Last, R.L., 2000. Identification of ascorbic aciddeficient Arabidopsis thaliana mutants. Genetics 154, 847-856.

Davey, M.W., Van Montagu, M., Inze, D., Sanmartin, M., Kanellis, A., Smirnoff, N., Benzie, I.J.J., Strain, J.J., Favell, D., Fletcher, J., 2000. Plant L-ascorbic acid: chemistry, function, metabolism, bioavailability and effects of processing. J. Sci. Food Agric. 80, 825-860.

Diallinas, G., Pateraki, I., Sanmartin, M., Scossa, A., Stilianou, E., Panopoulos, N.J., Kanellis, A.K., 1997. Melon ascorbate oxidase: cloning of a multigene family, induction during fruit development and repression by wounding. Plant Mol. Biol. 34, 759-770.

El-Sharkawy, I., Manriquez, D., Flores, F.B., Regad, F., Bouzayen, M., Latche, A., Pech, J. C., 2005. Functional characterization of a melon alcohol acyl-transferase gene family involved in the biosynthesis of ester volatiles. Identification of the crucial role of a threonine residue for enzyme activity*. Plant Mol. Biol. 59, 345-362.

Esaka, M., Fujisawa, K., Goto, M., Kisu, Y., 1992. Regulation of ascorbate oxidase expression in pumpkin by auxin and copper. Plant Physiol 100, 231-237.

Fang, G., Grumet, R., 1990. Agrobacterium tumefaciens mediated transformation and regeneration of muskmelon plants. Plant Cell Rep. 9, 160-164.

Fenech, M., Amaya, I., Valpuesta, V., Botella, M.A., 2018. Vitamin C content in fruits: biosynthesis and regulation. Front. Plant Sci. 9, 2006.

Ferjani, A., Ishikawa, K., Asaoka, M., Ishida, M., Horiguchi, G., Maeshima, M., Tsukaya, H., 2013. Enhanced cell expansion in a KRP2 overexpressor is mediated by increased V-ATPase activity. Plant Cell Physiol. 54, 1989-1998.

Flores, F., Ben Amor, M., Jones, B., Pech, J.C., Bouzayen, M., Latche, A., Romojaro, F., 2001. The use of ethylene-suppressed lines to assess differential sensitivity to ethylene of the various ripening pathways in Cantaloupe melons. Physiol. Plantarum $113,128-133$.

Fotopoulos, V., Sanmartin, M., Kanellis, A.K., 2006. Effect of ascorbate oxidase overexpression on ascorbate recycling gene expression in response to agents imposing oxidative stress. J. Exp. Bot. 57, 3933-3943.

Foyer, C.H., Noctor, G., 2005. Redox homeostasis and antioxidant signaling: a metabolic interface between stress perception and physiological responses. Plant Cell 17, 1866-1875.

Foyer, C.H., Kyndt, T., Hancock, R.D., 2020. Vitamin C in plants: novel concepts, new perspectives, and outstanding issues. Antioxid Redox Signal 32, 463-485.

Galaz, S., Morales-Quintana, L., Moya-Leon, M.A., Herrera, R., 2013. Structural analysis of the alcohol acyltransferase protein family from Cucumis melo shows that enzyme activity depends on an essential solvent channel. FEBS J. 280, 1344-1357.

De Gara, L., Tommasi, F., 1999. Ascorbate redox enzymes: a network of reactions involved in plant development. Rec. Dev. Phytochem. 1-15.

Garchery, C., Gest, N., Do, P.T., Alhagdow, M., Baldet, P., Menard, G., Rothan, C., Massot, C., Gautier, H., Aarrouf, J., Fernie, A.R., Stevens, R., 2013. A diminution in ascorbate oxidase activity affects carbon allocation and improves yield in tomato under water deficit. Plant Cell Environ. 36, 159-175.

Gonzalez-Reyes, J.A., Hidalgo, A., Caler, J.A., Palos, R., Navas, P., 1994. Nutrient uptake changes in ascorbate free radical-stimulated onion roots. Plant Physiol 104, 271-276.

Guis, M., Roustan, J.-P., Dogimont, C., Pitrat, M., Pech, J.-C., 1998. Melon Biotechnology, Biotechnology and Genetic Engineering Reviews 15, 289-312.

Holsters, M., de Waele, D., Depicker, A., Messens, E., van Montagu, M., Schell, J., 1978 Transfection and transformation of Agrobacterium tumefaciens. Mol. Gen. Genet. $163,181-187$.

Ioannidi, E., Kalamaki, M.S., Engineer, C., Pateraki, I., Alexandrou, D., Mellidou, I., Giovannonni, J., Kanellis, A.K., 2009. Expression profiling of ascorbic acid-related genes during tomato fruit development and ripening and in response to stress conditions. J. Exp. Bot. 60, 663-678.
Kato, N., Esaka, M., 1999. Changes in ascorbate oxidase gene expression and ascorbate levels in cell division and cell elongation in tobacco cells. Physiol Plant 105, 321-329.

Kato, N., Esaka, M., 2000. Expansion of transgenic tobacco protoplasts expressing pumpkin ascorbate oxidase is more rapid than that of wild-type protoplasts. Planta 210, 1018-1022.

Kerk, N.M., Feldman, L.J., 1995. A biochemical model for the initiation and maintenance of the quiescent center: implications for organization of root meristems. Development 121, 2825-2833.

Kjellbom, P., Larsson, C., 1984. Preparation and polypeptide composition of chlorophyllfree plasma membranes from leaves of light-grown spinach and barley. Physiol. Plantarum 62, 501-509.

Lester, G.E., Stein, E., 1993. Plasma membrane physicochemical changes during maturation and postharvest storage of muskmelon fruit. J. Am. Soc. Hortic. Sci. 118, 223-227.

Lin, L.S., Varner, J.E., 1991. Expression of ascorbic acid oxidase in zucchini squash (Cucurbita pepo L.). Plant Physiol 96, 159-165.

Liso, R., Calabrese, G., Bitonti, M.B., Arrigoni, O., 1984. Relationship between ascorbic acid and cell division. Exp. Cell Res. 150, 314-320.

Lyons, T., Ollerenshaw, J.H., Barnes, J.D., 1999. Impacts of ozone on Plantago major: apoplastic and symplastic antioxidant status. New Phytol. 141, 253-263.

Macknight, R.C., Laing, W.A., Bulley, S.M., Broad, R.C., Johnson, A.A., Hellens, R.P., 2017. Increasing ascorbate levels in crops to enhance human nutrition and plant abiotic stress tolerance. Curr. Opin. Biotechnol. 44, 153-160.

Mellidou, I., Kanellis, A.K., 2017. Genetic control of ascorbic acid biosynthesis and recycling in horticultural crops. Front Chem 5, 50.

Mellidou, I., Keulemans, J., Kanellis, A.K., Davey, M.W., 2012a. Regulation of fruit ascorbic acid concentrations during ripening in high and low vitamin $\mathrm{C}$ tomato cultivars. BMC Plant Biol. 12, 239.

Mellidou, I., Chagne, D., Laing, W.A., Keulemans, J., Davey, M.W., 2012b. Allelic variation in paralogs of GDP-L-galactose phosphorylase is a major determinant of vitamin C concentrations in apple fruit. Plant Physiol 160, 1613-1629.

Mellidou, I., Koukounaras, A., Chatzopoulou, F., Kostas, S., Kanellis, A., 2017. Plant Vitamin C: one single molecule with a plethora of roles. In: Elhadi, M.Y. (Ed.), Fruit and Vegetable Phytochemicals: Chemistry and Human Health. Wiley and Sons, Inc., USA.

Mellidou, I., Georgiadou, E., Kaloudas, D., Kalaitzis, P., Fotopoulos, V., Kanellis, A., 2019. Vitamins. In: Yahia, E.M. (Ed.), Postharvest Physiology and Biochemistry of Fruits and Vegetables. Elsevier Inc., pp. 359-383

Moser, O., Kanellis, A.K., 1994. Ascorbate oxidase of Cucumis melo L. var. reticulatus: purification, characterization and antibody production. J. Exp. Bot. 45, 717-724.

Murashige, T., Skoog, F., 1962. A revised medium for rapid growth and bio assays with tobacco tissue cultures. Physiol. Plantarum 15, 473-497.

Nishiyama, K., Guis, M., Rose, J.K., Kubo, Y., Bennett, K.A., Wangjin, L., Kato, K., Ushijima, K., Nakano, R., Inaba, A., Bouzayen, M., Latche, A., Pech, J.C., Bennett, A. B., 2007. Ethylene regulation of fruit softening and cell wall disassembly in Charentais melon. J. Exp. Bot. 58, 1281-1290.

Pallanca, J.E., Smirnoff, N., 2000. The control of ascorbic acid synthesis and turnover in pea seedlings. J. Exp. Bot. 51, 669-674.

Park, S.O., Hwang, H.Y., Crosby, K.M., 2009. A Genetic Linkage Map Including Loci for Male Sterility, Sugars, and Ascorbic Acid in Melon, in.

Pignocchi, C., Fletcher, J.M., Wilkinson, J.E., Barnes, J.D., Foyer, C.H., 2003a. The function of ascorbate oxidase in tobacco. Plant Physiol 132, 1631-1641.

Pignocchi, C., Fletcher, J.M., Wilkinson, J.E., Barnes, J.D., Foyer, C.H., 2003b. The function of ascorbate oxidase in tobacco. Plant Physiol 132, 1631-1641.

Plumb, W., Townsend, A.J., Rasool, B., Alomrani, S., Razak, N., Karpinska, B., Ruban, A. V., Foyer, C.H., 2018. Ascorbate-mediated regulation of growth, photoprotection, and photoinhibition in Arabidopsis thaliana. J. Exp. Bot. 69, 2823-2835.

Rose, J.K.C., Hadfield, K.A., Labavitch, J.M., Bennett, A.B., 1998. Temporal sequence of cell wall disassembly in rapidly ripening melon fruit. Plant Physiol 117, 345-361.

Sambrook, J., Fistch, E.F., Maniatis, T., 1989. Molecular Cloning: A Laboratory Manual. Cold Spring Harbour Laboratory Press, Cold Spring Harbour, New York.

Sanmartin, M., Drogoudi, P.A., Lyons, T., Pateraki, I., Barnes, J., Kanellis, A.K., 2003. Over-expression of ascorbate oxidase in the apoplast of transgenic tobacco results in altered ascorbate and glutathione redox states and increased sensitivity to ozone. Planta 216, 918-928.

Sanmartin, M., Pateraki, I., Chatzopoulou, F., Kanellis, A.K., 2007. Differential expression of the ascorbate oxidase multigene family during fruit development and in response to stress. Planta 225, 873-885.

Smirnoff, N., 1996. The function and metabolism of ascorbic acid in plants. Ann. Bot. (Lond.) 78, 661-669.

Smirnoff, N., 2000. Ascorbic acid: metabolism and functions of a multi-facetted molecule. Curr. Opin. Plant Biol. 3, 229-235.

Smirnoff, N., 2018. Ascorbic acid metabolism and functions: a comparison of plants and mammals. Free Radic. Biol. Med. 122, 116-129.

Smirnoff, N., Wheeler, G.L., 2000. Ascorbic acid in plants: biosynthesis and function. Crit. Rev. Biochem. Mol. Biol. 35, 291-314.

Stevens, R., Buret, M., Duffe, P., Garchery, C., Baldet, P., Rothan, C., Causse, M., 2007. Candidate genes and quantitative trait loci affecting fruit ascorbic acid content in three tomato populations. Plant Physiol 143, 1943-1953.

Stevens, R., Page, D., Gouble, B., Garchery, C., Zamir, D., Causse, M., 2008. Tomato fruit ascorbic acid content is linked with monodehydroascorbate reductase activity and tolerance to chilling stress. Plant Cell Environ. 31, 1086-1096.

Svent-Györgi, A., 1931. On the function of hexuronic acid in the respiration of the cabbage leaf. Biochem. J. 90, 385-393. 
Takahama, U., Oniki, T., 1992. Regulation of peroxidase-dependent oxidation of phenolics in the apoplast of spinach leaves by ascorbate. Plant Cell Physiol. 33, 379-387.

Terry, M.J., Williams, L.E., 2002. Fractionation of plant tissue for biochemical analyses. In: Gilmartin P, B.C. (Ed.), Molecular Plant Biology. Oxford University Press, Oxford, pp. 147-171.

Truernit, E., Haseloff, J., 2008. A simple way to identify non-viable cells within living plant tissue using confocal microscopy. Plant Methods 4, 15.

De Tullio, M.C., 2020. Is ascorbic acid a key signaling molecule integrating the activities of 2-oxoglutarate-dependent dioxygenases? Shifting the paradigm. Environ. Exp. Bot. 178, 104173.

De Tullio, M.C., Guether, M., Balestrini, R., 2013. Ascorbate oxidase is the potential conductor of a symphony of signaling pathways. Plant Signal. Behav. 8, e23213.

Veljovic-Jovanovic, S.D., Pignocchi, C., Noctor, G., Foyer, C.H., 2001. Low ascorbic acid in the vtc-1 mutant of Arabidopsis is associated with decreased growth and intracellular redistribution of the antioxidant system. Plant Physiol 127, 426-435.

Venkatesh, J., Park, S.W., 2014. Role of L-ascorbate in alleviating abiotic stresses in crop plants. Bot. Stud. 55, 38.
Villalba, J.M., Cordoba, F., Navas, P., 1996. Ascorbate and the plasma membrane. A new view of cell growth control. Subcell. Biochem. 25, 57-58.

Wang, D., Yeats, T.H., Uluisik, S., Rose, J.K.C., Seymour, G.B., 2018. Fruit softening: revisiting the role of pectin. Trends Plant Sci. 23, 302-310.

Wheeler, G.L., Jones, M.A., Smirnoff, N., 1998. The biosynthetic pathway of vitamin C in higher plants. Nature 393, 365-369.

Yamamoto, A., Bhuiyan, M.N., Waditee, R., Tanaka, Y., Esaka, M., Oba, K., Jagendorf, A. T., Takabe, T., 2005. Suppressed expression of the apoplastic ascorbate oxidase gene increases salt tolerance in tobacco and Arabidopsis plants. J. Exp. Bot. 56, 1785-1796.

Yoshida, K., Ito, T., Nozawa, H., Ohkawa, J., Shinmyo, A., 1994. Sequence requirement of 5 '-upstream region of the ascorbate oxidase gene for organ-specific expression in cucumber. Ann. N. Y. Acad. Sci. 721, 245-247.

Yu, Y., Wang, J., Li, S., Kakan, X., Zhou, Y., Miao, Y., Wang, F., Qin, H., Huang, R., 2019. Ascorbic acid integrates the antagonistic modulation of ethylene and abscisic acid in the accumulation of reactive oxygen species. Plant Physiol 179, 1861-1875.

Zhang, Y.Y., Li, H.X., Shu, W.B., Zhang, C.J., Zhang, W., Ye, Z.B., 2011. Suppressed expression of ascorbate oxidase gene promotes ascorbic acid accumulation in tomato fruit. Plant Mol. Biol. Rep. 29, 638-645. 